\title{
Insulin-like Growth Factor-1 Receptor Dictates Beneficial Effects of Treadmill Training by Regulating Survival and Migration of Neural Stem Cell Grafts in the Injured Spinal Cord
}

\author{
Dong Hoon Hwang ${ }^{1 *}$, Hee Hwan Park ${ }^{1,3}$, Hae Young Shin ${ }^{1,4}$, \\ Yuexian Cui ${ }^{1,5}$ and Byung Gon Kim ${ }^{1,2,3 *}$ \\ ${ }^{1}$ Department of Brain Science, Ajou University School of Medicine, Suwon 16499, ${ }^{2}$ Department of Neurology, Ajou University \\ School of Medicine, Suwon 16499, ${ }^{3}$ Neuroscience Graduate Program, Department of Biomedical Sciences, Ajou University \\ School of Medicine, Suwon 16499, ${ }^{4}$ Logos Biosystems, Anyang 14055, Korea, ${ }^{5}$ Department of Neurology, Yanbian University \\ Hospital, Yanji 133000, Jilin, China
}

\begin{abstract}
Survival and migration of transplanted neural stem cells (NSCs) are prerequisites for therapeutic benefits in spinal cord injury. We have shown that survival of NSC grafts declines after transplantation into the injured spinal cord, and that combining treadmill training (TMT) enhances NSC survival via insulin-like growth factor-1 (IGF-1). Here, we aimed to obtain genetic evidence that IGF-1 signaling in the transplanted NSCs determines the beneficial effects of TMT. We transplanted NSCs heterozygous (+/-) for Igfl $r$, the gene encoding IGF-1 receptor, into the mouse spinal cord after injury, with or without combining TMT. We analyzed the influence of genotype and TMT on locomotor recovery and survival and migration of NSC grafts. In vitro experiments were performed to examine the potential roles of IGF-1 signaling in the migratory ability of NSCs. Mice receiving +/- NSC grafts showed impaired locomotor recovery compared with those receiving wild-type (+/+) NSCs. Locomotor improvement by TMT was more pronounced with +/+ grafts. Deficiency of one allele of Igflr significantly reduced survival and migration of the transplanted NSCs. Although TMT did not significantly influence NSC survival, it substantially enhanced the extent of migration for only $+/+$ NSCs. Cultured neurospheres exhibited dynamic motility with cytoplasmic protrusions, which was regulated by IGF-1 signaling. IGF-1 signaling in transplanted NSCs may be essential in regulating their survival and migration. Furthermore, TMT may promote NSC graft-mediated locomotor recovery via activation of IGF-1 signaling in transplanted NSCs. Dynamic NSC motility via IGF-1 signaling may be the cellular basis for the TMT-induced enhancement of migration.
\end{abstract}

Key words: Spinal cord injury, Neural stem cell, Treadmill training, Insulin-like growth factor-1, Migration, Motility

Received October 26, 2018, Revised December 13,2018,

Accepted December 14,2018

* To whom correspondence should be addressed.

Dong Hoon Hwang, TEL: 82-31-219-4561, FAX: 82-31-219-4444

e-mail:drhdh@ajou.ac.kr

Byung Gon Kim, TEL: 82-31-219-4495, FAX: 82-31-219-4444

e-mail:kimbg@ajou.ac.kr

\section{INTRODUCTION}

Transplantation of neural stem cells (NSCs) or progenitors, either primary or derived from pluripotent stem cells, is one of the most promising strategies that may lead to meaningful functional
Copyright $($ ) Experimental Neurobiology 2018. www.enjournal.org
This is an Open Access article distributed under the terms of the Creative Commons Attribution Non-Commercial License (http://creativecommons.org/licenses/by-nc/4.0) which permits unrestricted non-commercial use, distribution, and reproduction in any medium, provided the original work is properly cited. 
recovery in disabled patients with spinal cord injury (SCI). Multiple mechanisms, including provision of growth factors, immune modulation, and replacement of myelin-forming oligodendrocytes, have been proposed to explain the preclinical benefits of NSC transplantation [1-5]. Recently, a series of studies proposed the exciting possibility that NSCs can participate in the formation of alternative neural circuits, conveying supraspinal input to the spinal motor center [6-9]. For grafted NSCs to integrate into the novel networks, a sufficient number would have to survive and migrate to appropriate positions to establish synaptic connections. However, achieving an adequate level of survival and migration of NSCs in the injured CNS is a daunting task. Previous studies have reported that a large fraction of transplanted NSCs die and that extent of migration is frequently limited [1, 10-15].

Activity-based neurorehabilitation has proven its potential in improving functional recovery after SCI [16-18]. Furthermore, it has been demonstrated that activation of the spinal motor circuit using various neuromodulation tools is effective in restoring lost motor functions [19-22]. We have previously noticed that combined treadmill training (TMT) substantially enhanced survival of NSC grafts in the lesioned spinal cord [23]. Given the increasing relevance of activity-based therapies in SCI, elucidating the mechanisms underlying the interactions between biological behaviors of NSCs and neurorehabilitation interventions would have profound implications in designing future therapeutic strategies for functional repair of the injured spinal cord.

We previously reported that TMT increased the level of IGF-1 in cerebrospinal fluid and that intrathecal infusion of neutralizing antibodies against IGF-1 markedly attenuated TMT-induced enhancement of NSC graft survival in the lesioned spinal cord, suggesting the involvement of IGF-1 signaling in the enhancement of NSC survival by TMT [23]. The current study was designed to obtain genetic evidence of cell-autonomous roles of IGF-1 signaling in transplanted NSCs to determine their biology such as survival and migration in the lesioned spinal cord. We hypothesized that IGF-1 signaling in transplanted NSCs would have more profound consequences when recipient animals are subjected to TMT. To this end, we utilized haploinsufficiency of Igflr, the gene encoding IGF-1 receptor (IGF-1R), in NSCs since previous studies have shown that deficiency of one allele of IgfIr leads to significant alteration of IGF-1R-dependent metabolic outcomes [24]. We generated and transplanted NSCs heterozygous for Igflr in injured mice, with or without combined TMT, and analyzed the influence of genetic and TMT factors on the locomotor recovery and biological behaviors of NSC grafts in the lesioned spinal cord.

\section{MATERIALS AND METHODS}

\section{Culture of Igflr-heterozygous NSCs}

All experiments were conducted in accordance with the approval of the Institutional Animal Care and Use Committee of Ajou University School of Medicine. The manuscript has been prepared following the ARRIVE guidelines. Mice of the Igflrknockout strain (B6.129-IGF-1 $\mathrm{r}^{\mathrm{tm} 1.2 \mathrm{Mhz}} / \mathrm{Orl}$, \#EM:00115) were purchased from European Mouse Mutant Archive (EMMA). Mice of the DsRed.T3 strain (B6.Cg-Tg(CAG-DsRed ${ }^{*}$ MST) 1 Nagy/ J, \#006051), which constitutively express the red fluorescent protein (RFP) variant DsRed.MST, were purchased from the Jackson Laboratory. To distinguish transplanted NSCs from resident cells in the spinal cord, Igflr-heterozygous mice were crossed with the Ds.Red.T3 line. To generate Igf1r-heterozygous NSCs, heterozygous males were crossed with wild-type females; the resulting embryos were used to obtain NSCs. Mouse NSCs were cultured as previously described, with a slight modification for mice [23]. Briefly, the spinal cords of embryos at day 14 were dissected under a dissecting microscope (Carl Zeiss). The spinal cord tissue from each embryo was placed on a separate dish and incubated individually in Accumax dissociation medium (Thermo Fisher Scientific) at room temperature for $10 \mathrm{~min}$. After centrifugation, dissociated cells were plated in StemPro ${ }^{\circledR}$ NSC serum-free culture medium (Thermo Fisher Scientific) containing basic fibroblast growth (bFGF, $20 \mathrm{ng} / \mathrm{ml}$ ) and epidermal growth factor (EGF, 20 $\mathrm{ng} / \mathrm{ml}$ ). Immediately after plating, genotypes of the embryos were determined using REDExtract-N-Amp ${ }^{\text {TM }}$ Tissue PCR Kit (Sigma). Subsequently, NSCs from the embryos of the same genotypes were collected and cultured together from then on.

\section{Neurosphere assay and in vitro NSC survival assay}

Neurosphere assay was performed following a previously published protocol [25]. Tertiary neurospheres, which are formed after two passages, were used for measurement of the number and size of neurospheres. Secondary neurospheres from each group were collected and centrifuged, and the supernatant was removed. Then, Accumax dissociation medium was added, and the neurospheres were incubated for $5 \mathrm{~min}$. Dissociated cells were plated at a density of $10^{5}$ cells per $100 \mathrm{~mm}$ petri dish. Culture medium was changed every day, with fresh bFGF and EGF added during the entire culture period. Neurospheres were allowed to grow for 7 days, after which the number and size of tertiary spheres were determined. Four independent cultures were used for the neurosphere assay. Neurospheres were counted under a confocal microscope (FV300, Olympus) at a $10 \times$ magnification, with a minimum cutoff diameter of $20 \mu \mathrm{m}$. Three images were randomly 
acquired from each plate, and the diameter of the neurospheres in these images was measured using the Image J software. For in vitro NSC survival assay, dissociated NSCs cultured in a 96-well plate were exposed to either $400 \mu \mathrm{M}$ 3-morpholinosydnonimine (SIN1, Enzo Life Sciences, Inc.) or $1 \mathrm{mM}$ hydrogen peroxide $\left(\mathrm{H}_{2} \mathrm{O}_{2}\right.$, Sigma), which produce reactive nitrogen species (RNS) or reactive oxygen species (ROS), respectively. Nitric oxide (NO)-associated radical species can kill transplanted NSCs in the injured spinal cord, and SIN-1 was used to produce RNS to damage cultured NSCs [26]. $\mathrm{H}_{2} \mathrm{O}_{2}$ has been frequently used to induce oxidative stress in stem cells $[27,28]$. Cultured NSCs were incubated in medium containing either $\mathrm{SIN}-1$ or $\mathrm{H}_{2} \mathrm{O}_{2}$ for $48 \mathrm{~h}$ with or without IGF- 1 at a concentration of $20 \mathrm{ng} / \mathrm{ml}$. Three independent cultures were performed per experimental condition $(\mathrm{N}=3)$, with each culture replicated thrice. The percentage of surviving NSCs was determined using Cell Counting Kit-8 (Dojindo Laboratories) according to the manufacturer's instructions.

\section{Surgical procedures and cellular transplantation}

Nine-week-old C57BL/6 females (20 25 g) (Orient Bio), which had completed 1 week of treadmill pretraining (see below), were subjected to a contusion injury. Animals were anesthetized by intraperitoneal injection of ketamine $(90 \mu \mathrm{g} / \mathrm{g})$ and xylazine $(10 \mu \mathrm{g} /$ g) mixture. After laminectomy was performed, the dorsal surface of the spinal cord at the $9^{\text {th }}$ vertebral level was injured using the Infinite Horizon Impactor (Precision Systems and Instrumentation), with a force of $70 \mathrm{kdyn}$. Subsequently, animals were randomly divided into 4 groups depending on whether they received NSC grafts that were wild-type $(+/+)$ or heterozygous $(+/-)$ for Igflr gene, or whether they underwent further TMT. Therefore, the 4 groups consisted of: 1) mice receiving +/+ grafts without TMT, 2) mice receiving +/+ grafts with TMT, 3 ) mice receiving +/- grafts without TMT, and 4) mice receiving +/- grafts with TMT. Transplantation of NSCs was performed 1 week after contusion injury. Immediately before transplantation, tertiary neurospheres were dissociated and resuspended at a density of $10^{5} \mathrm{cells} / \mu \mathrm{l}$. Two injections were administered at $2 \mathrm{~mm}$ rostral and caudal to the epicenter using a Hamilton syringe configured with a glass micropipette (tip diameter $<70 \mu \mathrm{m}$ ). The injection lasted for $3 \mathrm{~min}$, being controlled by a nanoliter syringe pump (KD Scientific Inc.). The pipette was kept in situ for 2 more min to prevent leakage from the injection sites. Each injection consisted of $2.5 \times 10^{5}$ dissociated NSCs suspended in $2.5 \mu$ l of PBS $\left(5 \times 10^{5}\right.$ cells in total). After transplantation, animals were assigned randomized codes to ensure that experimenters were blinded to the graft genotype.

\section{Treadmill training}

We performed TMT using a 10-channel Flat Treadmill System for mice (model IW-FT, IWOO Scientific). Each channel consists of a $50 \times 450 \mathrm{~mm}$ runway. The TMT protocol adopted in our previous study [23] was slightly modified for mice. All animals received pretraining for 7 days before injury; TMT was initiated 3 days after injury for animals that were assigned to the groups with TMT. Most mice were able to exhibit spontaneous stepping by 7 days at a slow treadmill speed $(5 \mathrm{~m} / \mathrm{min})$. Temporarily suspended after transplantation, TMT was restarted 3 days later and continued until the animals were sacrificed for histological analysis. TMT was performed at a slow speed $(5 \mathrm{~m} / \mathrm{min})$ until animals regained weight-supported plantar stepping, and thereafter, the speed was gradually increased up to $10 \mathrm{~m} / \mathrm{min}$. The training was performed 6 days per week, with 3 sessions per day. Each session consisted of $20 \mathrm{~min}$ of training and $5 \mathrm{~min}$ of break. Mice assigned to the groups without TMT, they were handled and brought to the training room together with those in the groups with TMT, but excluded from the actual training.

\section{Behavioral assessment of locomotor recovery}

A total of 36 mice were included for the behavioral analysis with 9 animals per group. Basso Mouse Scale for locomotion (BMS), ladder walk test, and digitized gait analysis using the Catwalk system (Noldus Information Technology) were used to assess recovery of locomotor function. We assessed BMS $24 \mathrm{~h}$ after injury and once a week thereafter. For the ladder walk test, the animals were pretrained to walk on ladder rungs for 7 days before surgery, and tested 4 and 8 weeks after injury. The number of hind-paw placement errors per run was counted and the average percentage of errors was obtained from four runs for each animal. The Catwalk analysis was performed 8 weeks after injury. Animals were pretrained for walking on the Catwalk runway before surgery and retrained for 5 days before final testing. On the test day, 4 uninterrupted crossings were recorded. Before computerized analysis, individual footprints from 4 different paws were manually confirmed. The following parameters were automatically calculated: stride length, base of support, and rotation angle. The angle of hind-paw rotation was defined as the angle (in degrees) of the hind-paw axis relative to the horizontal plane. As described previously [23], the relative position of the fore-paws and hind-paws was obtained by measuring the distance between the center pads of the fore-paw and hind-paw prints.

\section{Tissue processing and immunohistochemistry}

After cardiac perfusion with 4\% paraformaldehyde, the spinal cord was dissected and post-fixed, followed by cryoprotection 
in a graded series of sucrose solutions. Longitudinal sections (20 $\mu \mathrm{m}$-thick) of the spinal cord were cut using a cryostat (CM 1900, Leica) and thaw-mounted onto Super Frost Plus slides (Thermo Fisher Scientific). For immunohistochemistry, sections were incubated overnight at $4^{\circ} \mathrm{C}$ with the following primary antibodies: anti-RFP (1:500, mouse polyclonal; \#R10367, Invitrogen), antiadenomatous polyposis coli (APC) clone CC1 (APC-CC1) (1:200, mouse monoclonal; \#OP80, Calbiochem), anti-glial fibrillary acidic protein (GFAP) (1:500, rabbit polyclonal; \#Z0334, DAKO) and anti-doublecortin (DCX) (1:400, rabbit polyclonal; \#4604S, Cell Signaling Technology). After washing, slides were incubated with appropriate secondary antibodies conjugated to the Alexa Fluor fluorescent dyes. Slides were examined using a confocal laser scanning microscope (LSM 800, Carl Zeiss).

\section{Stereological counting of NSC grafts and quantitative im- age analysis}

Stereological cell counting was performed as previously described [23]. Longitudinal sections in a horizontal plane were systematically selected at an intersection interval of $300 \mu \mathrm{m}$ (section sampling fraction $=1 / 15$ ). The sampling grid dimension was $500 \times 500 \mu \mathrm{m}^{2}$ with a $200 \times 200 \mu \mathrm{m}^{2}$ counting grid (area sampling fraction=0.16). Using a dissector height of $10 \mu \mathrm{m}$ in sections with an average post-processing thickness of $18 \mu \mathrm{m}$, the height sampling fraction was $0.56(10 / 18)$. The migratory distance of RFPpositive grafts for each animal was determined as the longest longitudinal distance in either rostral or caudal direction from the epicenter out of 5 consecutive longitudinal sections with a $300-\mu \mathrm{m}$ intersection distance. It is conceivable that the longitudinal migratory distance can be influenced by the extent of graft survival; the more NSCs survive, the longer they distribute longitudinally. To control for the different extents of graft survival, a migration index was generated by dividing the longest longitudinal migratory distance by the longest transverse diameter of the RFP-positive area.

\section{In vitro migration assay}

The IGF-1-induced NSCs migration was assessed using Boyden chamber assay kit (CytoSelect $^{\mathrm{TM}}$ 24-well cell migration assay kit, \#CBA-107; CELL BIOLABS Inc.), where an upper chamber was separated from a well by a polycarbonate membrane insert (12$\mu \mathrm{m}$ pore size). Dissociated NSCs were plated on a culture insert nested inside of a 24 -well culture plate at a density of $5 \times 10^{4}$ cells/ well. StemPro ${ }^{\circledR}$ NSC serum-free medium containing bFGF and EGF was added to an upper chamber within an insert, while IGF1 was added as a chemoattractant to the same medium in a 24-well with the same insert. The Boyden chamber was incubated at $37^{\circ} \mathrm{C}$ with $5 \% \mathrm{CO}_{2}$ for 48 hours. After non-migratory cells on the up- per surface of the insert were removed by a cotton swab provided in the kit, migratory cells attached to the bottom side of the insert were stained using the cell-staining solution provided in the kit for $10 \mathrm{~min}$ at room temperature. The rate of NSCs migration was calculated by counting cells in 3 random fields of each well using a $10 \times$ objective lens (BX51, Olympus). For in vitro scratch assay, dissociated NSCs were plated on a 24 -well culture plate coated with Poly-D-lysine at a density of $5 \times 10^{4}$ cells. StemPro ${ }^{\circledR}$ NSC serum-free medium containing bFGF and EGF was added and maintained throughout the imaging session without changing. An artificial scratch was created with a white $10-\mu$ pipette tip at the center of the mono-layered cultured cells. NSCs migrating toward the scratch were monitored real-time for up to 4 consecutive days using JuLI ${ }^{\mathrm{TM}}$ Stage (NanoEntek). Areas occupied by migrating cells within the scratch were automatically calculated by JuLI ${ }^{\mathrm{TM}}$ STAT software.

\section{Neurosphere motility assay}

Neurospheres derived from Igflr $(+/+)$ or (+/-) NSCs were seeded on a 24-well culture plate with $1 \mathrm{ml}$ of StemPro ${ }^{\circledR}$ NSC serumfree medium containing bFGF and EGF. Approximately 50 to 100 neurospheres were present in each well. Culture medium was not changed during the entire imaging period to prevent perturbation of neurospheres floating in the medium. Time-lapse images were obtained using JuLI ${ }^{\mathrm{TM}}$ Stage for 4 days to visualize spontaneous neurosphere movement and changes in cytoplasmic protrusions extending from neurospheres. To trace spontaneous motile paths of neurospheres, the center of a neurosphere was manually marked in every image acquired at 30-min intervals using the Manual Tracking plugin in Image J, and this software calculated the summed moving distances of the center of each neurosphere. To measure the extent of changes in filopodia-like cytoplasmic protrusions, the tip of the longest protrusion from each neurosphere traced for the moving paths was also manually marked, and the Manual Tracking plugin calculated the summed length of the changes in tip position. Three randomly selected fields of view were determined in each live imaging experiment. We traced 4 to 6 neurospheres in each imaging session that were clearly identified and delineated for at least 3-hour duration. Quantified data were collected from three independent live imaging experiments for each experimental condition. To examine the influence of IGF-1 and related signaling pathways on the neurosphere motility, IGF1 (50 ng/ml, \#791-MG, R\&D Systems), phosphoinositide-3 kinase (PI3K) inhibitor (LY294002; $10 \mu \mathrm{M}$, \#440202, CalbioChem), mitogen-activated protein kinase/extracellular signal-regulated kinase (MEK/ERK) inhibitor (U0126; $10 \mu \mathrm{M}$, \#662005, CalbioChem), Rho-associated protein kinase (ROCK) inhibitor (Y27632; 
$10 \mu \mathrm{g} / \mathrm{ml}$, \#129830-38-2, Tocris), IGF-1R inhibitor (PPP, picropodophyllin; $100 \mu \mathrm{M}$, \#SC-204008, Santa Cruz Biotechnology) were added in culture medium.

\section{Statistical analysis}

Error bars in all graphs represent mean \pm standard error of mean (SEM). Statistical analysis was performed using GraphPad Prism (version 5.0) and SPSS software (version 23). Unpaired Student's $t$ test or one-way ANOVA was used for comparison of group means. Repeated-measures two-way ANOVA was used to compare mean differences matched at different time points. Two-way ANOVA followed by post hoc Bonferroni analysis was used to test statistical significance of genotype and TMT factors on behavioral outcomes and survival and migration of transplanted NSCs in the injured spinal cord.

\section{RESULTS}

\section{In vitro properties of Igf1r-heterozygous NSCs}

To examine influence of IGF-1/IGF-1R signaling on transplanted NSCs in the lesioned spinal cord, we attempted to generate NSCs with deleted IgfIr gene. Since IgfIr-homozygous knockout mice die at birth [24,29], we initially crossed heterozygous male and female mice to produce embryos for primary NSC cultures. But the number of litter was very small, and the frequency of Igfl $r$ homozygous genotype was much lower in 14-day-old embryos than that expected by the Mendelian principle. Therefore, heterozygous males were crossed with wild-type females to obtain IgfIrheterozygous (+/-) NSCs. Neurospheres generated from +/- NSCs exhibited similar size (Fig. 1A) and number (Fig. 1B) compared to those from wild-type (+/+) NSCs, indicating that only one allele of Igflr gene is sufficient to maintain the stemness of NSCs.

We have previously observed that transplanted NSCs at the epicenter region in the spinal cord are under RNS- and ROS-induced cellular stresses [23]. Treatment of either +/+ or +/- NSCs with
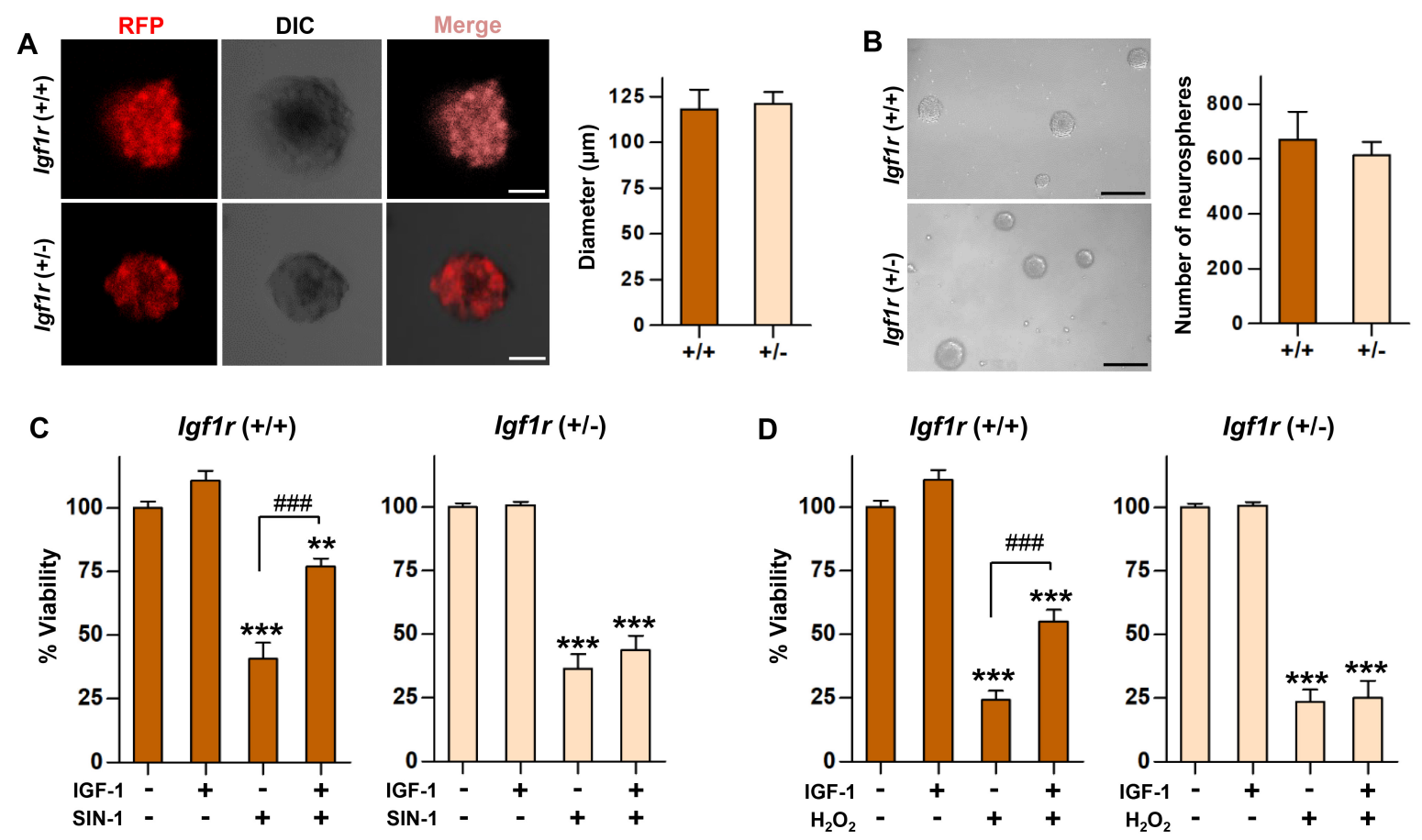

Fig. 1. In vitro properties of Igf1r-heterozygous NSCs. (A) Representative images of neurospheres derived from NSCs wild-type (+/+) and heterozygous (+/-) for Igflr gene. Since Igf1r-heterozygous line was crossed with DsRed.T3 strain, all neurospheres emit intense red fluorescence. Scale bars indicate $50 \mu \mathrm{m}$. Quantification graph comparing mean diameters of $+/+$ and $+/$ - neuropsheres. $\mathrm{N}=4$ independent cultures for each group. (B) Representative bright-field images at a lower magnification. Scale bars indicate $100 \mu \mathrm{m}$. Quantification graph comparing the number of $+/+$ and $+/$ - neuropsheres. $\mathrm{N}=4$ independent cultures for each group. (C, D) In vitro survival assays. NSCs were exposed to either 3-morpholinosydnonimine (SIN-1, $400 \mu \mathrm{M})(\mathrm{C})$ or $\mathrm{H}_{2} \mathrm{O}_{2}(1 \mathrm{mM})(\mathrm{D})$ for $48 \mathrm{~h}$ with or without IGF-1 $(20 \mathrm{ng} / \mathrm{ml})$. The percentage of viable cells in the treatment groups was expressed as the percent value compared with that of control condition (without any treatment). $\mathrm{N}=4$ independent cultures per group. ${ }^{* *}$ and ${ }^{* * *}$ represent $\mathrm{p}<0.01$ and $\mathrm{p}<0.001 \mathrm{com}$ pared to control condition, and \#\#\# represents $\mathrm{p}<0.001$ comparing SIN-1 (C) or $\mathrm{H}_{2} \mathrm{O}_{2}$ (D) exposure groups with or without IGF- 1 treatment by one-way ANOVA followed by Tukey's post hoc analysis at each time point. 
SIN-1 or $\mathrm{H}_{2} \mathrm{O}_{2}$, generating RNS or ROS, respectively, significantly reduced the number of viable NSCs (Fig. 1C, D). Addition of IGF1 to the culture medium significantly prevented RNS- or ROSinduced NSC death, while IGF-1 treatment did not increase the number of NSCs without cellular stresses. The IGF-1-induced robust pro-survival effects were almost completely abrogated in +/NSCs (Fig. 1C, D). These data suggest that deleting only one allele of Igflr gene profoundly attenuates the responsiveness of NSCs to IGF-1 under cellular stresses.

\section{Influence of IGF-1R in transplanted NSCs and TMT on lo- comotor recovery}

We assessed whether IGF-1R signaling in transplanted NSCs could affect TMT-supported locomotor recovery of mice following contusion injury. Half the animals received $+/+$ NSC grafts and the other received $+/$ - grafts, and half the animals in each graft group underwent TMT up to 8 weeks after transplantation.
The mice receiving +/+ NSC grafts began to exhibit improved locomotor quality, as measured using BMS, compared with those receiving +/- grafts at 3 weeks after injury and thereafter (Fig. 2A). TMT effect on BMS was noted at 4 weeks and thereafter in mice with $+/+$ NSC grafts, showing the best recovery of BMS in mice that received $+/+$ grafts and underwent TMT. Mice that received +/- grafts also exhibited gradual improvement in locomotor function, but the extent of recovery was inferior to that of the $+/+$ graft group. Although TMT effect was also observed in mice with +/- NSC grafts, TMT-induced recovery was delayed and less pronounced in this group than that in the $+/+$ graft group. Repeated-measures two-way ANOVA revealed a significant interaction between treatment conditions and the time points after SCI $(\mathrm{p}<0.001)$. Post hoc Bonferroni analysis showed statistically significant difference between +/+ NSC grafts with TMT and +/without TMT groups (Fig. 2A). Furthermore, the difference in BMS score improvement between mice with $+/+$ and $+/$ - NSC
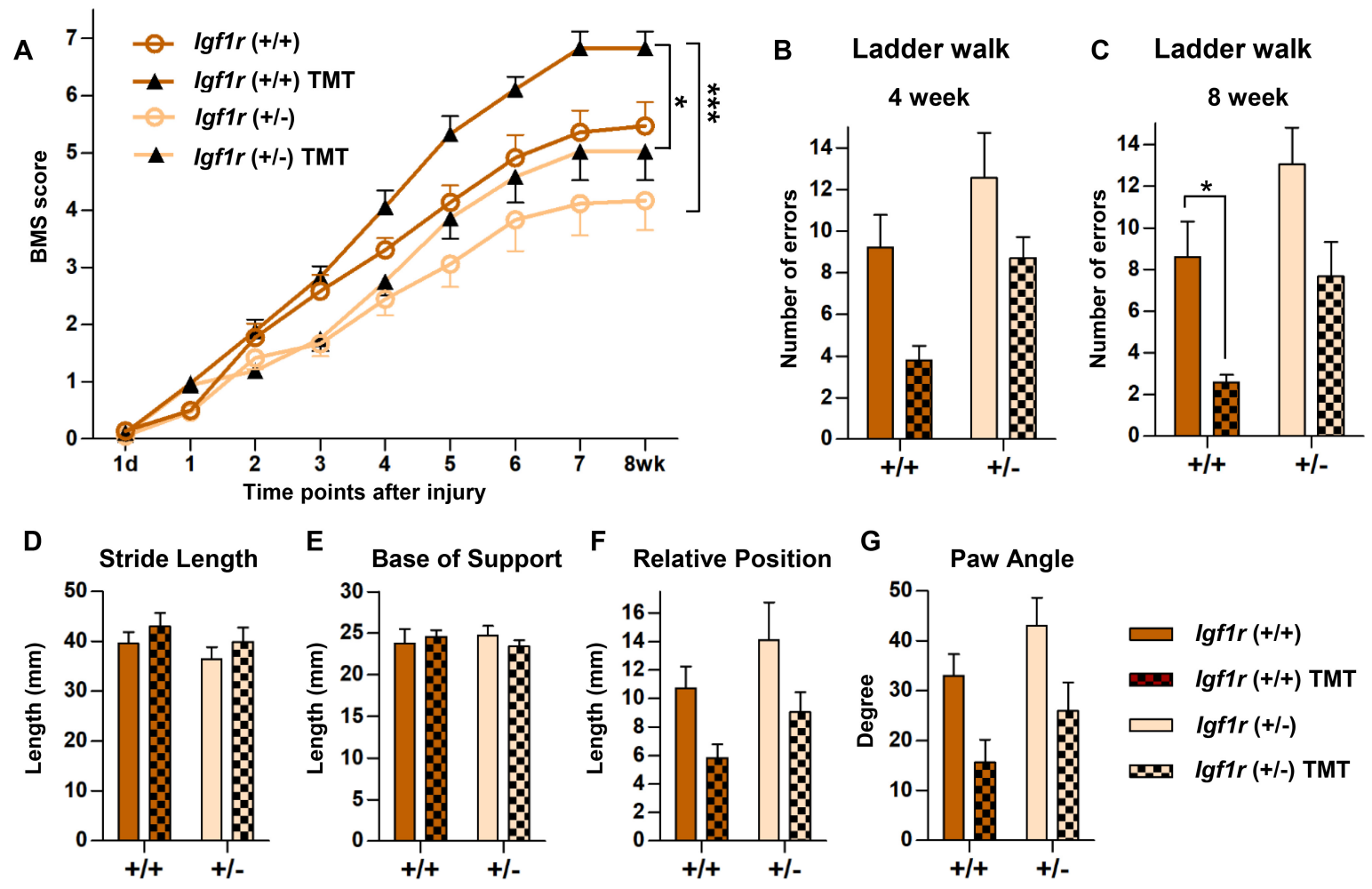

Fig. 2. Influence of IGF-1R in transplanted NSCs and treadmill training (TMT) on locomotor recovery. (A) Recovery of BMS (Basso Mouse Scale for locomotion) scores over the 8-week period after injury. Animals with transplanted NSCs wild-type $(+/+)$ for Igflr gene and combined treadmill training (TMT) together showed the best locomotor recovery. ${ }^{*}$ and ${ }^{* * *}$ represent $\mathrm{p}<0.05$ and $\mathrm{p}<0.001$ by repeated-measures two-way ANOVA followed by post hoc Bonferroni analysis. N=9 animals for each group. (B, C) Ladder walk test at 4 (B) and 8 weeks (C) after injury. The number of hind-paw placement errors was counted at the 4 - (B) and 8-week (C) time points. ${ }^{*}$ represents $\mathrm{p}<0.05$ by two-way ANOVA followed by post hoc Bonferroni analysis. $\mathrm{N}=9$ animals for each group. (D G) Catwalk automated footprint analysis assessed at 8 weeks after SCI. The graphs show (D) stride length (distance between the two consecutive hind-paw footprints), (E) base of support (width between the left and right hind-paws), (F) relative position (distance between the center pads of fore- and hind-paw prints), and (G) rotation angle (angle of the hind-paw axis relative to the horizontal plane). $\mathrm{N}=9$ animals for each group. 
grafts was statistically significant in animals subjected to TMT (Fig. 2A). In contrast, BMS scores in different genotypes were not significantly different in animals without TMT, suggesting that genotype-dependent improvement of BMS score was more evident in animals subjected to TMT. However, the differences in BMS score between the same genotype groups, whether it is $+/+$ or +/- group, with and without TMT were not statistically significant by post hoc Bonferroni test.

In the ladder walk test, mice that received +/+ NSC grafts tended to exhibit hind-paw placement errors less frequently than those with +/-grafts, regardless of TMT, at both 4- and 8-week time points (Fig. 2B, C). TMT reduced the number of errors in both genotype groups, but more evidently in $+/+$ graft group, resulting in the smallest number of errors in mice with $+/+$ grafts as well as TMT. At both time points, the effects of both genotype and TMT factors were statistically significant by two-way ANOVA (4week genotype, $F_{(1,32)}=7.816, \mathrm{p}=0.009$; 4 -week TMT, $F_{(1,32)}=9.811$, $\mathrm{p}=0.004 ; 8$-week genotype, $F_{(1,32)}=10.294, \mathrm{p}=0.003 ; 8$-week TMT, $\left.F_{(1,32)}=14.586, \mathrm{p}=0.001\right)$. Post hoc Bonferroni test did not reveal statistically significant TMT effect for either genotype at 4 weeks

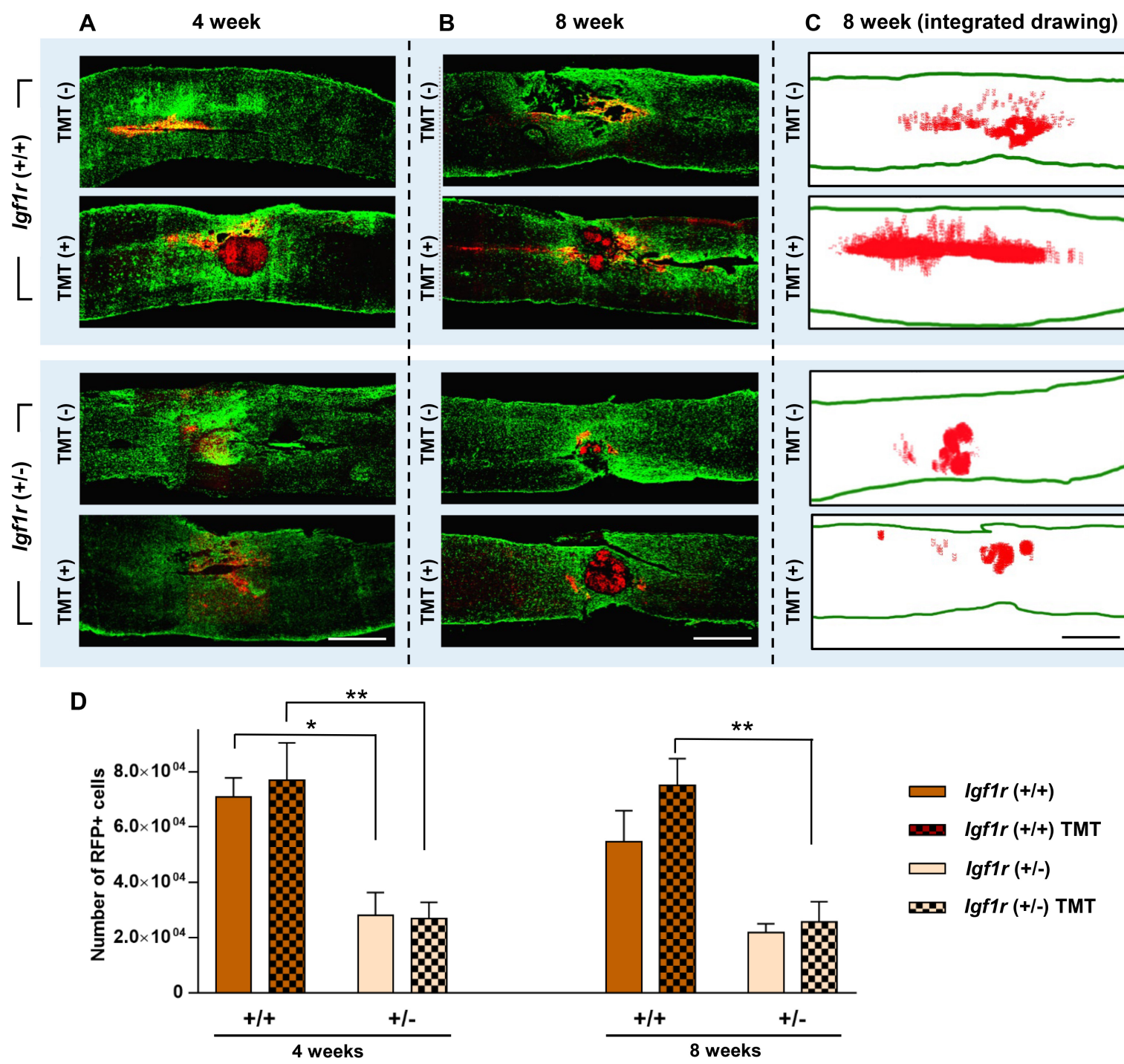

Fig. 3. Survival of NSC grafts in the injured spinal cord. (A, B) Representative images of longitudinal spinal cord sections at 4 (A) or 8 weeks (B) after injury. Spinal cord sections were immunostained with anti-RFP (red) and anti-glial fibrillary acidic protein (GFAP; green) antibodies to visualize the distribution of the transplanted NSCs in relation to the lesions. Scale bars indicate $1 \mathrm{~mm}$. (C) Representative integrated drawing of stereologically counted RFP-positive NSCs at the 8-week time point. RFP-positive NSCs from 5 longitudinal sections $300 \mu \mathrm{m}$ apart from each other were integrated in one image. The structural outlines of the spinal cord tissue in the integrated images were obtained from the most middle section in each animal. Scale bar indicates $1 \mathrm{~mm}$. (D) Quantification graphs of the number of surviving NSCs at 4 and 8 weeks after injury. $\mathrm{N}=5$ and 9 animals at 4 and 8 weeks, respectively, for each group. ${ }^{*}$ and ${ }^{* *}$ represent $\mathrm{p}<0.05$ and $\mathrm{p}<0.01$, respectively, by two-way ANOVA followed by post hoc Bonferroni analysis. 
(Fig. 2B). At 8 weeks, however, TMT effect was significant only in mice with $+/+$ NSC grafts ( $\mathrm{p}=0.045$ ) (Fig. 2C), indicating that TMT significantly supported accuracy of hind-paw placement in the ladder walk test when Igflr (+/+) NSCs were transplanted. Among the four parameters in the Catwalk analysis, neither stride length nor base of support was affected by genotype or TMT factors (Fig. 2D, E). Relative position, which is indicative of coordination between fore- and hind-paws, was markedly reduced by TMT in both genotype groups (Fig. 2F). Mice with +/+ NSC grafts and TMT together showed the lowest value, indicating the greatest recovery of fore- and hind-paw coordination in this group. Similar findings were noted upon measurement of the paw angle (Fig. $2 \mathrm{G})$. TMT factor was statistically significant for both measures, as revealed by two-way ANOVA (relative position, $F_{(1,32)}=8.109$, $\mathrm{p}=0.008$; paw angle, $\left.F_{(1,32)}=11.580, \mathrm{p}=0.002\right)$. However, post hoc Bonferroni test did not reveal statistically significant TMT effect for either genotype in the measurements of relative position and paw angle (Fig. 2F, G). Although a trend of worse performance (higher values) in both measures was noted in mice with +/- NSC grafts, the effect of genotype was not statistically significant. Taken together, these behavioral data indicated that transplanting Igflr $(+/+)$ NSCs combined with TMT could achieve the highest locomotor recovery, and that TMT-supported functional improvement was significant in mice with +/+ NSC grafts in the ladder walk test.

\section{Survival of NSC grafts in the injured spinal cord}

We compared the survival of NSC grafts heterozygous for Igflr to that of wild-type NSC grafts following transplantation into the injured spinal cord, and examined whether TMT affected the survival of either genotype NSCs. Surviving NSCs were identified by RFP expression, and then the number of RFP-positive cells was stereologically counted. Four weeks after transplantation, a considerable number of RFP-positive grafts were visualized not only around the epicenter but also in distant regions caudal or rostral to the epicenter in mice with +/+ NSC grafts (Fig. 3A). However, the extent of NSC survival was only approximately $10 \sim 15 \%$ of the total transplanted cells $\left(5 \times 10^{5}\right)$ (Fig. 3D), indicating substantial demise of transplanted NSCs during the post-transplantation period. The survival of +/- NSC grafts was more profoundly decreased, with most of the surviving NSCs being present only at the epicenter areas (Fig. 3A). Survival of transplanted NSCs only slightly diminished by the 8-week time point, indicating that the loss of NSCs predominantly occurred early after transplantation. Being subjected to TMT or not did not lead to appreciable difference in the survival of either $+/+(70920 \pm 6861$ vs. $76950 \pm 13490$ cells, without or with TMT, respectively) or $+/-(28170 \pm 8136$ vs. $26790 \pm 5971$ cells, without or with TMT, respectively) NSCs at 4 weeks (Fig. 3A, D). At 8 weeks, a similar pattern of NSC survival was noted, with a genotype-dependent decrease in the number of surviving NSCs (Fig. 3B, C). There was no noticeable beneficial effect of TMT on the survival of +/- NSC grafts (21760 \pm 3265 vs. $25562 \pm 7437$ cells, without or with TMT, respectively), while it tended to increase the survival of +/+ NSCs $(54620 \pm 11289$ vs. $75047 \pm 9676$ cells, without or with TMT, respectively) especially in distant regions caudal or rostral to the epicenter. Quantitative analysis revealed that only the genotype effect was statistically significant at both time points by two-way ANOVA (4-week, $F_{(1,16)}=26.087, \mathrm{p}<0.001$; 8-week, $\left.F_{(1,32)}=23.623, \mathrm{p}<0.001\right)$. Although TMT increased the survival of $+/+$ grafts by $37.4 \%$ at 8 weeks (Fig. 3D), TMT effect was not statistically significant $\left(F_{(1,32)}=2.045, \mathrm{p}=0.162\right)$. However, post hoc Bonferroni test revealed that the genotype effect was statistically significant only between the groups subjected to TMT (Fig. 3D), suggesting that the genotype effect was more obvious when animals underwent TMT. Transplanted NSCs, either heterozygous or wild-type for Igflr gene, differentiated into three neural cell types (Fig. 4A E). There was no discernable influence of TMT on differentiation of NSCs of either genotype.

\section{TMT affects IGF-1R-dependent migration of NSCs}

We found that different experimental conditions resulted in marked differences in the extent of NSC migration (Fig. 3). When we focused on the distance of the migrating NSCs from the epicenter, +/+ NSC grafts showed a tendency to migrate further than + - grafts, either rostrally or caudally, at 8 weeks after transplantation (Fig. 5A D). At this time point, mice that were subjected to TMT exhibited longer migration of +/+ NSCs (Fig. 5A, B). NSCs positioned at the leading edge of the grafts frequently showed elongation of cytoplasmic processes in a rostro-caudal direction. However, this influence of TMT was not obvious in mice that received +/- NSC grafts (Fig. 5C, D). Furthermore, elongated morphology was rarely observed in + /- NSCs. We obtained the migration index (the longest longitudinal migratory distance divided by the longest transverse diameter) for each animal from the longitudinal spinal cord section showing the longest migration. The effect of genotype on the migration index was already significant at 4 weeks by twoway ANOVA $\left(F_{(1,16)}=14.975, \mathrm{p}=0.001\right)$. Post hoc Bonferroni test revealed that the genotype factor was significant in animals subjected to TMT, but not in those without TMT (Fig. 5E). However, TMT factor was not statistically significant at this time point by two-way ANOVA $\left(F_{(1,16)}=1.281, \mathrm{p}=0.274\right)$. At 8 weeks, the migration index was markedly increased compared with 4 weeks only in animals with +/+ NSC grafts that were subjected to TMT. The influence of the genotype factor on the degree of migration was 


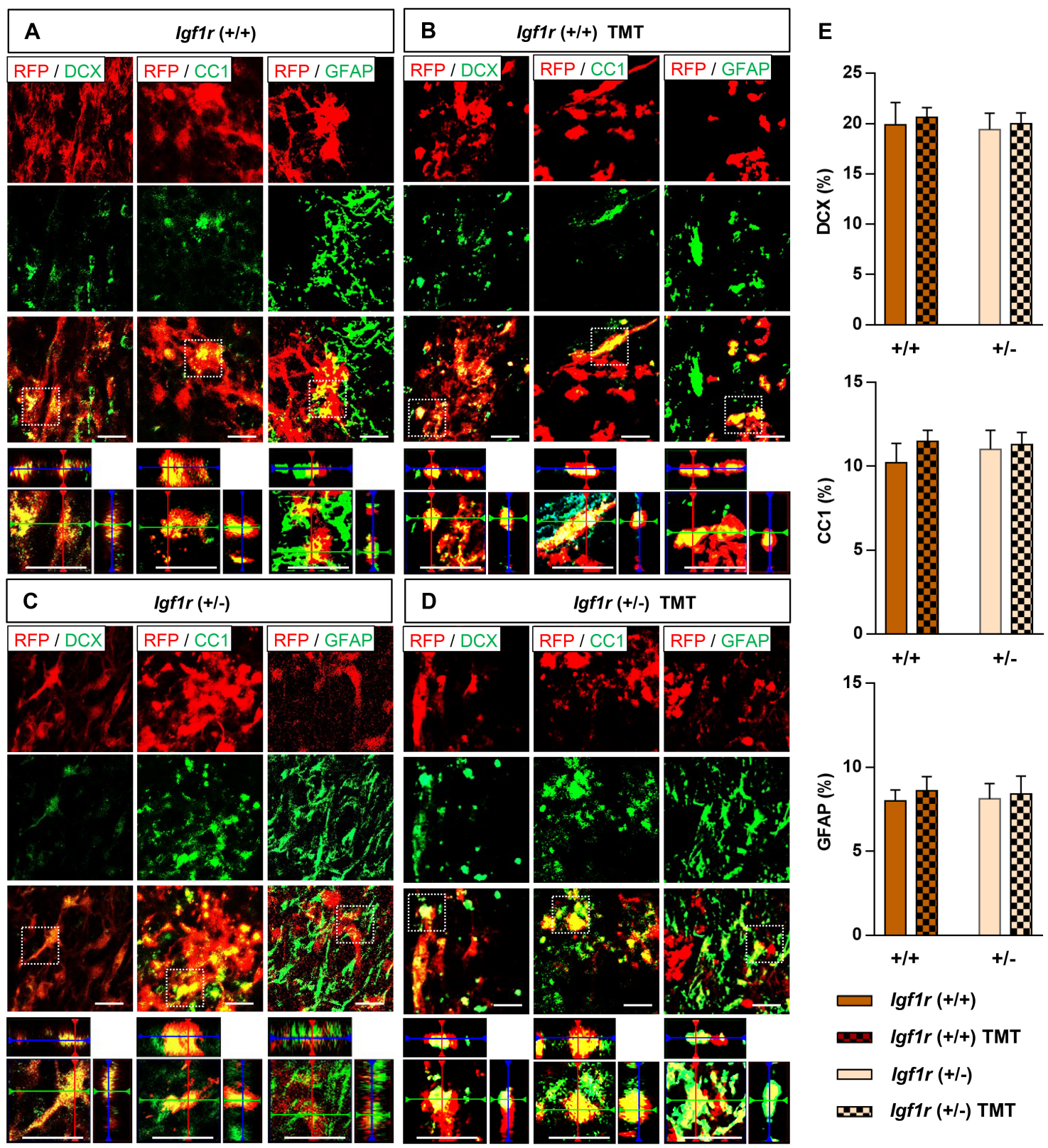

Fig. 4. Phenotypic differentiation of NSCs after transplantation into the injured spinal cord. (A D) Representative images of transplanted NSCs in the injured spinal cord from animals receiving Igflr $(+/+)$ NSC grafts with (C) or without (A) TMT, and from animals receiving Igflr (+/-) NSC grafts with (D) or without (B) TMT. Transplanted cells were identified by immunoreactivity to red fluorescence protein (RFP). Neural cell phenotypes were determined by immunoreactivity (green) for neuronal marker DCX, mature oligodendrocyte marker APC-CC1, and astrocytic marker GFAP. RFP-positive NSCs (red) colocalized with neural cell markers are shown in yellow. Higher magnification and orthographic projection images of the boxed regions are shown at the bottom of each panel. All scale bars indicate $20 \mu \mathrm{m}$. (E) Quantification graphs of the number of differentiated NSCs at 8 weeks after injury. $\mathrm{N}=9$ animals, for each group.

highly significant, as revealed by two-way ANOVA $\left(F_{(1,32)}=55.842\right.$, $\mathrm{p}<0.001)$. The TMT factor was also significant at this time point $\left(F_{(1,32)}=15.471, \mathrm{p}<0.001\right)$. Post hoc Bonferroni test revealed that the difference in the extent of migration between genotypes was statistically significant in animals with or without TMT (Fig. 5E). Importantly, the migration difference caused by TMT was statisti- cally significant only in animals with $+/+$ NSC grafts (Fig. 5E), indicating that TMT positively influenced the migration of NSCs that were $+/+$ for IgfIr. These data indicated that migration of NSC grafts is highly dependent on Igflr genotype at both 4 and 8 weeks after transplantation, and that TMT significantly enhanced the migration only when NSCs were homozygous for Igflr at the 

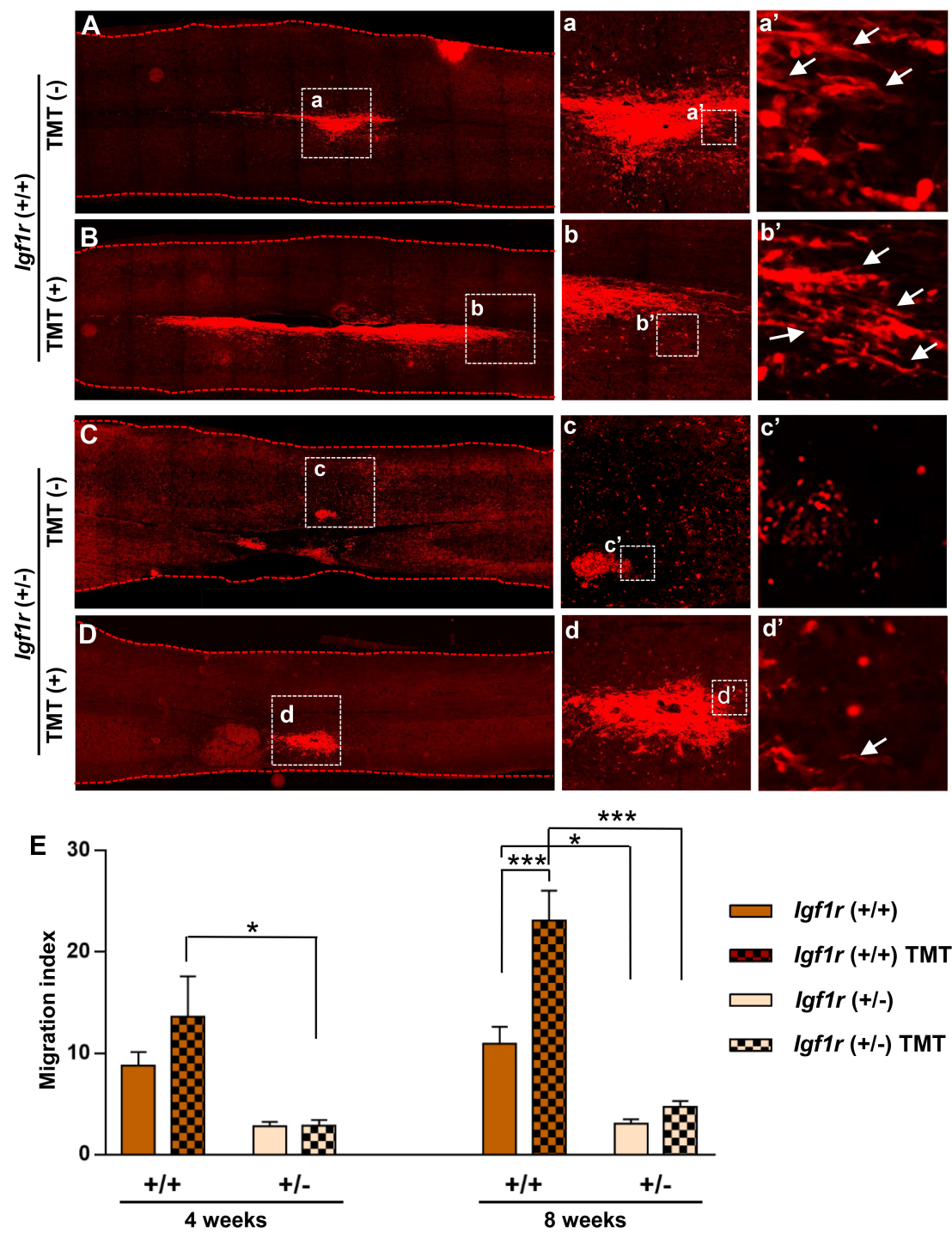

8-week time point.

\section{Implication of IGF-1 and IGF-1R in the migration ability of NSCs in vitro}

Given the crucial role of the Igflr genotype of NSCs and TMT in determining the extent of NSC migration in the lesioned spinal cord, we directly compared in vitro migratory ability between +/+ and +/- NSCs. In the Boyden chamber assay, +/+ NSCs occasionally migrated to the bottom side of the membrane without a concentration gradient of any chemoattractant (Fig. 6A). When IGF-1 was added to the lower chamber, the number of migrating cells markedly increased. The concentration gradient of IGF-1 in the lower chamber was still effective in promoting migration of +/- NSCs, but the basal migration ability was low in NSCs with only one copy of Igflr gene. Quantification showed that addition of IGF-1 significantly increased the number of migrating NSCs
Fig. 5. Treadmill training (TMT) enhances migration of NSCs in an IGF-1R-dependent manner. (A D) Representative images of longitudinal spinal cord sections at 8 weeks after injury. Spinal cord sections were immunostained with anti-RFP (red) antibodies to visualize transplanted NSCs in the injured spinal cord. Boxed regions are magnified in (a d). Scale bars indicate $500 \mu \mathrm{m}$. (a d) Magnified images of the boxed regions in (A D) showing NSC grafts that rostrally migrated. Scale bars indicate $200 \mu \mathrm{m}$. (a’ d') Magnified images of the boxed regions in (a d) showing migrating individual NSCs from the rostral grafts. Arrows indicated elongated cytoplasmic processes aligned with the direction of migration. Scale bars indicate $50 \mu \mathrm{m}$. (E) Quantification graphs comparing the extent of migration of NSCs at 4 and 8 weeks after injury. The migration extent was expressed as a migration index that was generated by dividing the longest longitudinal migratory distance by the longest transverse diameter of the RFP positive area. $\mathrm{N}=5$ and 9 animals at 4 and 8 weeks, respectively, for each group. ${ }^{*}$ and ${ }^{* * *}$ represent $\mathrm{p}<0.05$ and $\mathrm{p}<0.001$, respectively, by two-way ANOVA followed by post hoc Bonferroni analysis.

with both genotypes. However, the basal migratory ability of $+/$ NSCs was significantly lower than that of +/+ NSCs, and the number of cells migrating to the bottom side in response to IGF-1 was also significantly attenuated in $+/$ - NSCs (Fig. 6C). After a scratch injury at the center of NSC cultures on a 24-well plate, +/+ NSCs started to migrate to the scratch site as early as $6 \mathrm{~h}$, and more than $80 \%$ of the scratched area became occupied by migrating NSCs by $24 \mathrm{~h}$ (Fig. 6B, D). In contrast, +/- NSCs showed appreciable migratory behavior only approximately $24 \mathrm{~h}$ after the scratch, and only half the scratch area was occupied at $96 \mathrm{~h}$, the last time point examined (Fig. 6B, D). These results collectively suggest that IGF$1 \mathrm{can}$ act as a chemoattractant to NSCs, and IGF-1R signaling in NSCs is essential for their migratory behavior.

\section{IGF-1 signaling regulates NSC motility in vitro}

Previous studies have reported highly migratory behavior of 
A

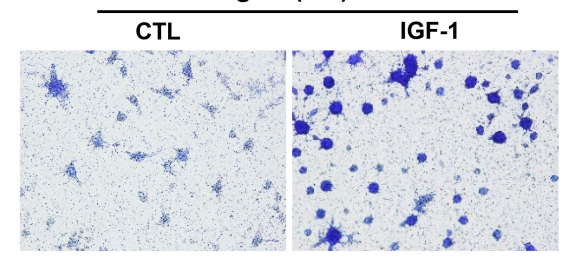

B $\quad \mathbf{~ h ~}$
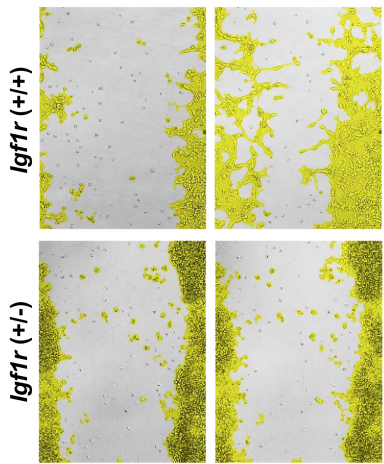

C

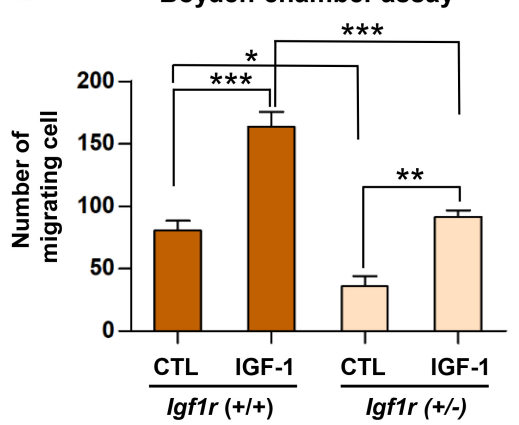

$12 \mathrm{~h}$
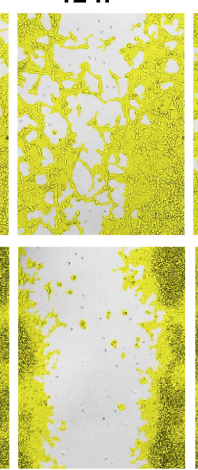

D

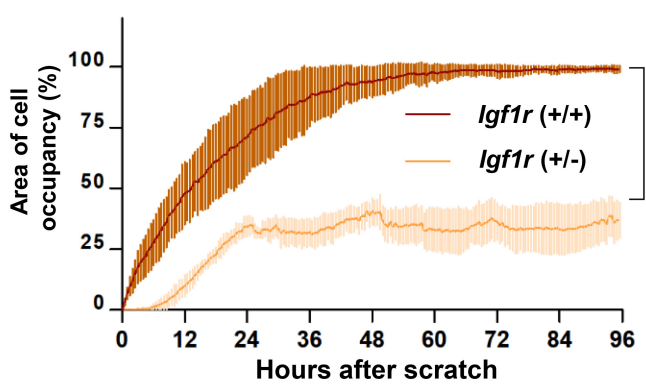

$\operatorname{lgf1r}(+/-)$

CTL IGF-1

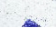

$18 \mathrm{~h}$

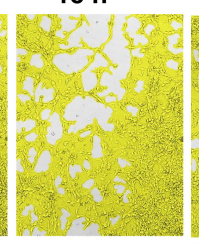

$24 \mathrm{~h}$
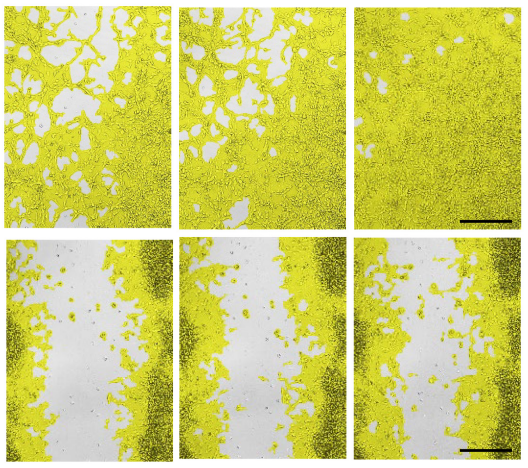

Scratch assay

Hours after scratch

$48 \mathrm{~h}$
政 chamber assay. ${ }^{*},{ }^{* *}$, and ${ }^{* * *}$ represent $\mathrm{p}<0.05, \mathrm{p}<0.01$, and $\mathrm{p}<0.001$, respectively, by one-way ANOVA followed by post hoc Tukey's analysis. $\mathrm{N}=4$ independent assays for each group. (D) Quantification graph of the scratch assay. Statistical analysis was done with the percent area of cell occupancy data obtained at 12 -h time intervals. ${ }^{* * *}$ represents $p<0.001$ by repeated measures twoway ANOVA followed by post hoc Bonferroni analysis. $\mathrm{N}=3$ independent assays for each group.
NSCs in vivo $[30,31]$, but it remains unclear whether NSCs are inherently motile, and if so, how their motility is regulated. Since basal migratory capacity of NSCs was observed in vitro (Fig. 6), we continuously monitored the behavior of cultured neurospheres using a live cell imaging apparatus. Surprisingly, wild-type neurospheres were highly motile (Supplementary video 1). The majority of neurospheres frequently changed their positions by a distance of up to several hundreds of micrometers (Fig. 7A), although not all neurospheres were motile. Individual NSCs occasionally migrated away from the original neurosphere; on the contrary, separate neurospheres occasionally merged together to form larger neurospheres (Supplementary video 1). The highly motile activity of neurospheres was accompanied by dynamic formation and/or retraction of cytoplasmic protrusions resembling filopodia or lamellipodia (Fig. 7B). The motile paths and the changes in cytoplasmic protrusions were quantified by tracking the marks at the center of neurospheres and tip of cytoplasmic protrusions, respectively (Fig. $7 \mathrm{~A} \sim \mathrm{C})$. The spontaneous motility of neurospheres with dynamic cytoplasmic protrusions were quite stable during the 4-day culture duration (Fig. 7D, E), indicating that the neurosphere motility was not a transient phenomenon due to a stabilization process following the initial plating of cells. To examine potential signaling pathways involved in the spontaneous motility of neurospheres, cultured neurospheres were treated with various pharmacological inhibitors (Fig. 8). The extent of both neurosphere movement and cytoplasmic protrusions were potently attenuated only by LY294002, a PI3K inhibitor.

Next, we tested whether IGF-1 signaling could regulate neurosphere motility. When IGF-1 was added to the culture medium, not only was the movement of individual neurospheres enhanced but also the proportion of motile neurospheres was increased (Fig. 9A, B) (Supplementary video 2). At the same time, cytoplasmic protrusions were much more dynamic in the IGF-1-treated condition. On the contrary, pharmacological inhibition of IGF-1R using PPP attenuated the extent of neurosphere movement and cytoplasmic protrusions (Fig. 9C) (Supplementary video 3). Finally, neurospheres obtained from NSCs (+/-) for Igflr gene exhibited very little motility (Fig. 9D) (Supplementary video 4). In particu- 

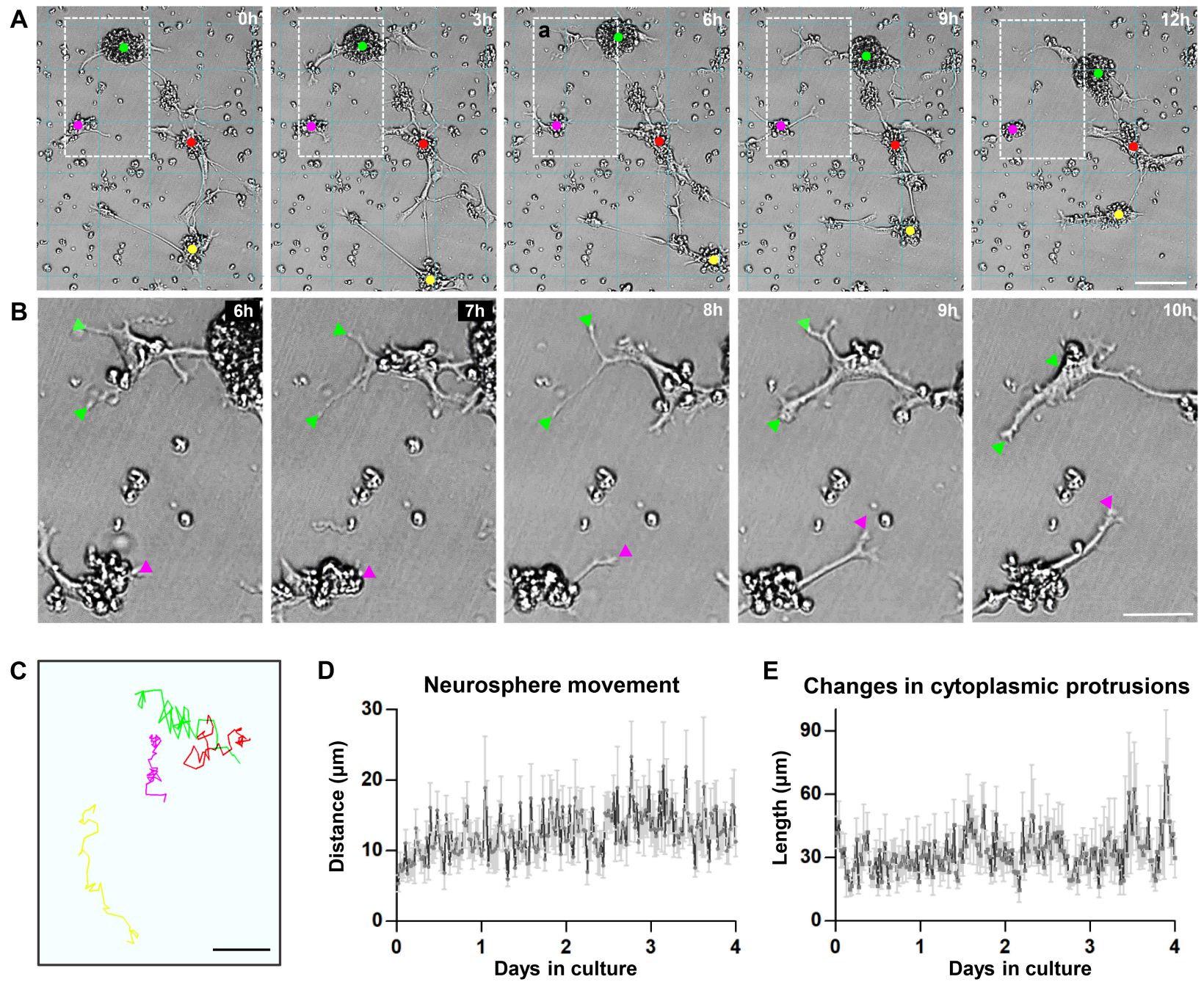

Fig. 7. Spontaneous motility of cultured neurospheres. (A) Representative still images of cultured neurospheres obtained using a live cell imaging apparatus. Images were acquired at the time points designated at the upper right corners. $0 \mathrm{~h}$ indicates a start of image tracking for the next $12 \mathrm{~h}$, not the absolute start of the culture. Grid lines were drawn to facilitate tracking positions of neurospheres. Colored dots indicate the marks of neurosphere centers that are traced to quantify distances of neurosphere movements. Neurospheres marked with dots of the same color in the images at different time points are the identical ones. Boxed area indicates the magnified regions in (B). Scale bar indicates $100 \mu \mathrm{m}$. (B) Magnified images at the regions boxed in (A). Images at a 1-h time interval (designated at the upper right corners) starting at the 6-h time point are presented. Arrowheads indicate the tips of cytoplasmic protrusions that are traced to quantify lengths of changes in cytoplasmic protrusions. The colors of arrowheads are the same as the ones for the center marks of the neurospheres in (A) which the protrusions belong to. (C) An exemplary drawing to illustrate motile paths of neurosphere centers tracked for 24 hours by an image analysis software. Different colors are used to illustrate motile paths of different individual neurospheres. Scale bar indicates $100 \mu \mathrm{m}$. (D, E) Quantification graphs of the moving distance (D) of the tracked neurospheres and the length of changes in cytoplasmic protrusions (E) growing from the tracked neurospheres. Each data point represents the distance moved or the length changed during the 30-minute period between two successive imaging sessions at every 30 minutes.

lar, cytoplasmic protrusions were rarely observed during the entire culture duration. Quantification results showed that IGF-1 and IGF-1R inhibitor significantly titrated the extent of +/+ neurosphere movement (Fig. 9E). Neurospheres heterozygous for Igflr exhibited severely suppressed movement. Furthermore, changes in cytoplasmic protrusions were reduced by more than 3 -fold in +/- neurospheres (Fig. 9F). These results collectively indicate that IGF-1/IGF-1R signaling in NSCs critically regulates inherent mo- tility that is highly likely to be the cellular basis of their migratory behavior in the injured spinal cord.

\section{DISCUSSION}

We have previously found that the IGF-1 concentration in cerebrospinal fluid was increased by almost three folds in animals with SCI following TMT with a protocol similar to the one used in this 

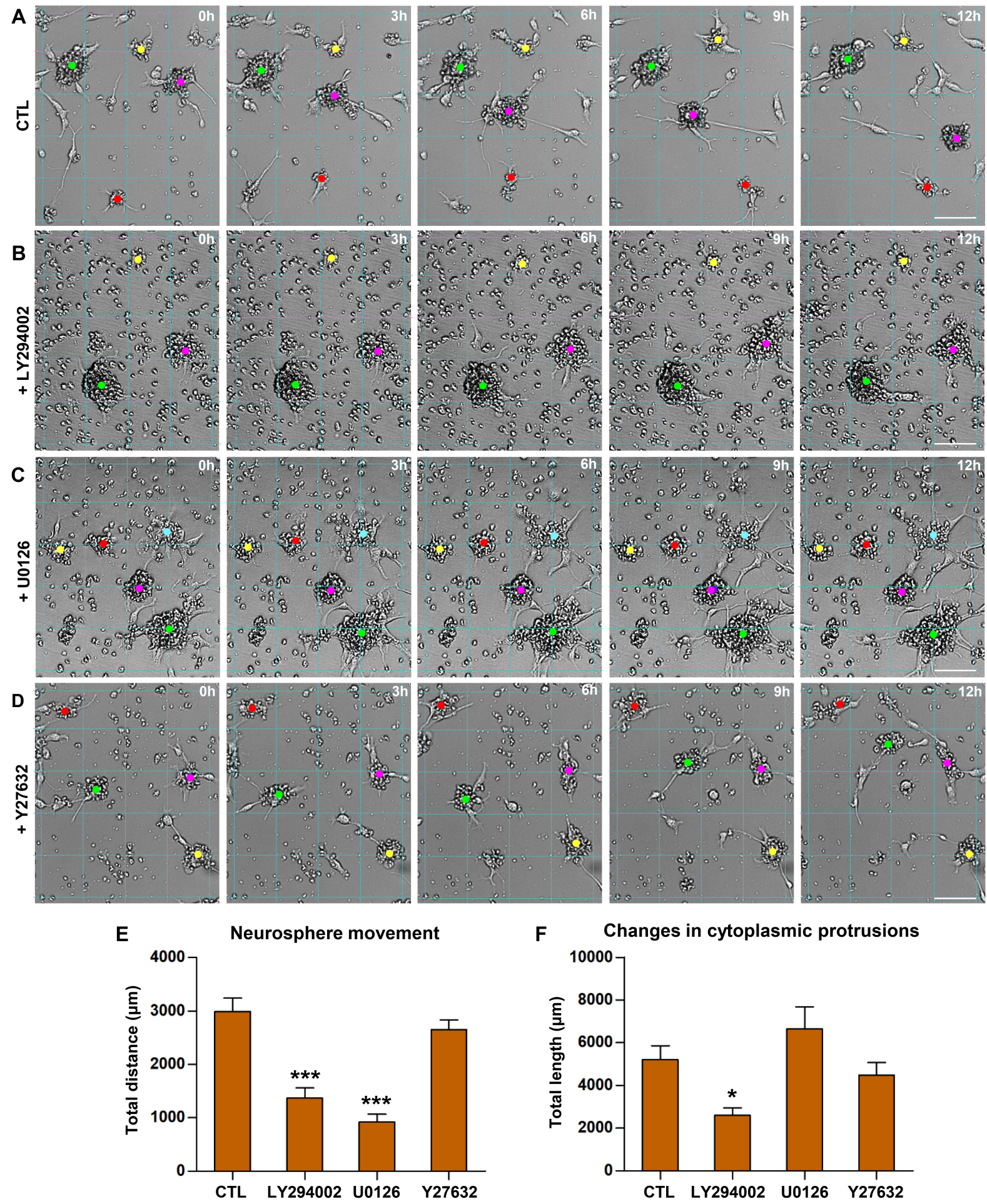

Fig. 8. Potential signaling pathways implicated in the spontaneous motility of neurospheres. (A D) Representative still images of cultured neurospheres obtained using a live cell imaging apparatus. Images were taken at the time points designated at the upper right corners. $0 \mathrm{~h}$ indicates a start of image tracking for the next $12 \mathrm{~h}$, not the absolute start of the culture. Neurospheres were treat with control (CTL) PBS (A), a PI3K inhibitor LY294002 (10 $\mu$ M) (B), an MEK/ERK inhibitor U0126 (10 $\mu \mathrm{M})(\mathrm{C})$, and a ROCK inhibitor Y27632 (10 $\mu \mathrm{g} / \mathrm{ml})(\mathrm{D})$. Grid lines were drawn to facilitate tracking positions of neurospheres. Colored dots indicate the marks of neurosphere centers that are traced to quantify distances of neurosphere movements. Neurospheres marked with dots of the same color in the images at different time points are the identical ones. Scale bars indicate $100 \mu \mathrm{m}$. (E, F) Quantification graphs of the moving distance (E) of the tracked neurospheres and the length of changes in cytoplasmic protrusions (F) growing from the tracked neurospheres. Total cumulative distance or length traced for the entire culture duration was plotted. $\mathrm{N}=15$ neurospheres tracked from three independent cultures. ${ }^{*}$ and ${ }^{* * *}$ represent $\mathrm{p}<0.05$ and $\mathrm{p}<0.001$ compared to CTL condition by one-way ANOVA followed by Tukey's post hoc analysis. 

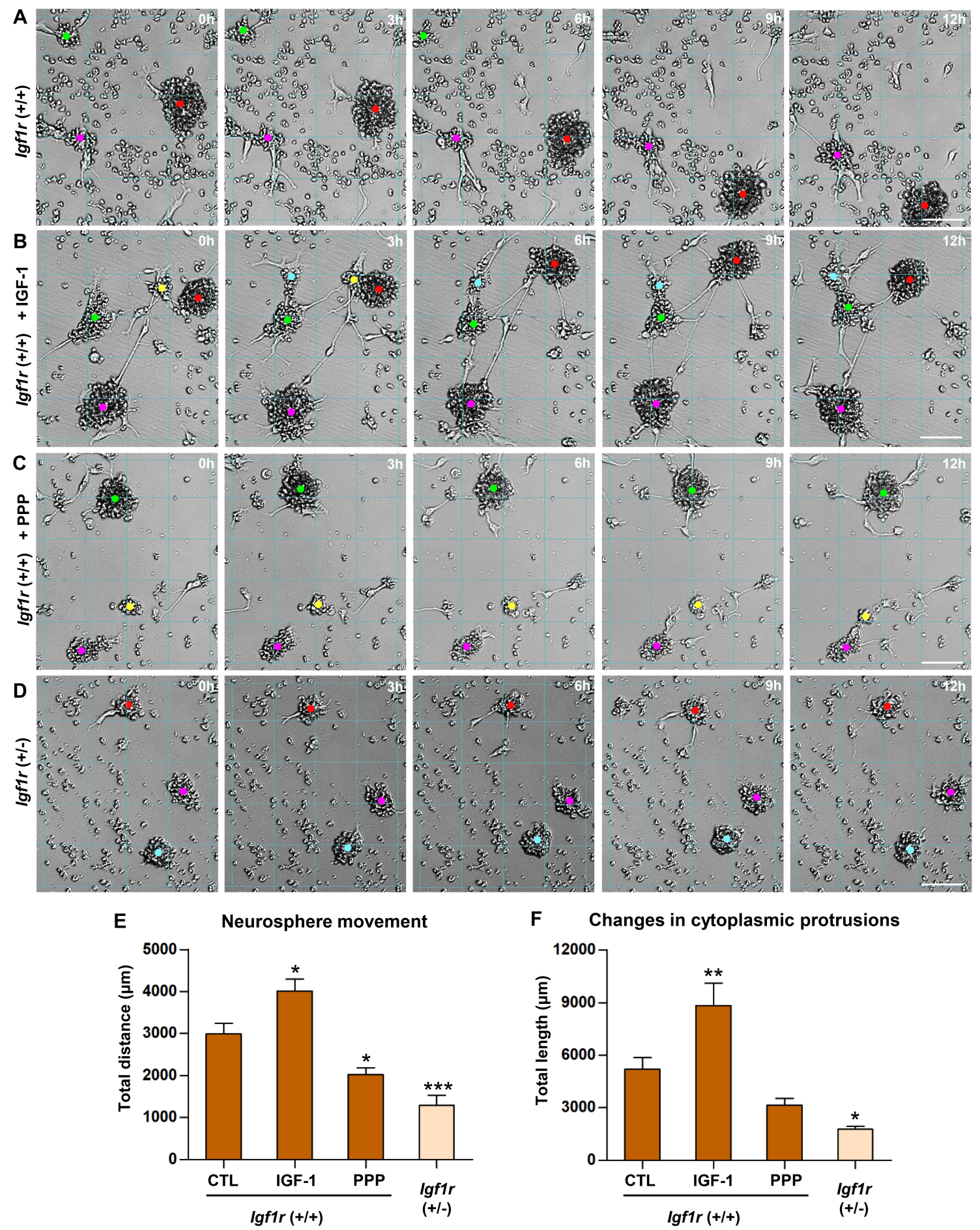

Fig. 9. Regulation of NSC motility by IGF-1/IGF-R signaling. (A D) Representative still images of cultured neurospheres obtained using a live cell imaging apparatus. Images were taken at the designated time points. $0 \mathrm{~h}$ indicates a start of image tracking for the next $12 \mathrm{~h}$, not the absolute start of the culture. Neurospheres were obtained from NSCs wild-type $(+/+)(\mathrm{A} \sim \mathrm{C})$ or heterozygous (+/-) (D) for Igflr gene. $+/+$ neurospheres were treated with control (CTL) PBS (A), IGF-1 (50 ng/ml) (B), or an IGF-1R inhibitor picropodophyllin (PPP, $100 \mu \mathrm{M})(\mathrm{C})$. (+/-) neurospheres were treated with only CTL PBS (D). Grid lines are drawn to facilitate tracking positions of neurospheres. Colored dots indicate the marks of neurosphere centers that are traced to quantify distances of neurosphere movements. Neurospheres marked with dots of the same color in the images at different time points are the identical ones. Scale bars indicate $100 \mu \mathrm{m}$. (E, F) Quantification graphs of the moving distance (E) of the tracked neurospheres and the length of changes in cytoplasmic protrusions (F) growing from the tracked neurospheres. Total cumulative distance or length traced for the entire culture duration was plotted. $\mathrm{N}=15$ neurospheres tracked from three independent cultures. ${ }^{*},{ }^{* *}$, and ${ }^{* * *}$ represent $\mathrm{p}<0.05, \mathrm{p}<0.01$, and $\mathrm{p}<0.001$ compared to $+/+\mathrm{CTL}$ condition by one-way ANOVA followed by Tukey's post hoc analysis. 
study [23]. We further demonstrated that the increased IGF-1 exerted protective effects on transplanted NSCs because intrathecal infusion of neutralizing antibodies against IGF-1 markedly attenuated TMT-induced enhancement of NSC graft survival [23]. The current study showed that the protective effects of IGF-1 were cellautonomous for transplanted NSCs through IGF-1R. Our experiments revealed that deficiency of one allele of Igfl $r$ in transplanted NSCs substantially impeded locomotor recovery compared to the animals transplanted with wild-type NSCs. The presence of a full complement of Igfl $r$ alleles was also critical in the survival and migration of transplanted NSCs. Combining TMT with transplantation of either +/+ or +/- NSCs enhanced the graft-mediated locomotor recovery, but the TMT effect was more pronounced with +/+ grafts. Furthermore, TMT substantially increased the extent of migration only for +/+ NSC grafts. These findings conclusively indicate that IGF-1 signaling in transplanted NSCs may be essential in regulating survival and migration of NSC grafts, and that TMT may enhance the graft-mediated locomotor recovery through activation of IGF-1 signaling in the transplanted NSCs.

In the behavioral assessment of locomotor recovery, improvement of BMS score was attenuated in mice that received +/- NSC grafts compared with those with $+/+$ grafts, demonstrating that the recovery of locomotor quality is dependent on the Igflr genotype in transplanted NSCs. TMT enhanced the improvement of BMS score regardless of whether the transplanted NSCs harbored $+/+$ or $+/$ - Igflr. This finding may suggest that TMT can contribute to behavioral recovery by mechanisms independent of those involving NSC grafts. Indeed, it is known that TMT promotes functional neuroplasticity of the spinal network involved in locomotion [32, 33]. Our previous study also showed that TMT alone significantly improves locomotor recovery without NSC grafts [23]. However, statistical analysis revealed that the effect of genotype on the improvement of BMS score was significant only when animals were subjected to TMT (Fig. 2A). This finding implies that a distinct mechanism underlies the influence of TMT on locomotor recovery through IGF-1 signaling in transplanted NSCs. The influence of TMT through IGF-1R in transplanted NSCs was more evident in the ladder walk test performed at 8 weeks (Fig. 2C), when the effect of TMT reached statistical significance only in animals with +/+ NSC grafts. Walking on a difficult runway, such as grid or ladder rungs, requires accurate sensorimotor integration that must be controlled to some extent by supraspinal inputs [34]. Therefore, the Igflr genotype-dependent influence of TMT on performance in the ladder walk test suggests that TMT-induced IGF-1 signaling in transplanted NSCs may ultimately participate in restoring supraspinal connections to the spinal locomotor circuits.

Although TMT tended to improve the survival of $+/+$ NSC grafts, the pro-survival effect of TMT was much less obvious in this study than that found in our previous study, where TMT enhanced the survival rate by more than 5-fold in rat SCI model [23]. In our previous study using a rat model, the basal (without TMT) survival rate of transplanted rat NSCs at 8 weeks was only 4.6\%, which was less than half of the survival rate in the mice that received +/+ NSCs without TMT (11.0\%). The higher basal survival rate in the current study could result in the reduction of TMT effects enhancing NSC survival. It is well known that a contusive injury leads to the formation of cystic cavities in rats but not in mice [35]. It is conceivable that the lack of tissue matrix would provide unfavorable influence on the survival of transplanted NSCs in a rat SCI model [36]. We also speculate that the requirement of IGF-1 signaling to support survival might be different between mouse and rat NSCs. IGF-1 signaling in mouse NSCs might be sufficiently active to support survival without the TMT-induced increase in the availability of IGF-1, whereas the increase in IGF1 levels might be essential to step up the activation status of IGF1 signaling in rat NSCs, leading to additional benefits for survival. In contrast to its influence on survival, TMT robustly influenced the migration of transplanted NSCs. The TMT effect was evident only in +/+ NSC grafts, suggesting that the TMT-induced enhancement of NSC migration may be highly dependent on IGF-1 signaling in transplanted NSCs. Therefore, it is possible that IGF1 signaling in mouse NSCs relevant to survival and migration may have a different threshold for full enactment; a low threshold for survival might make the further activation of IGF-1 signaling by TMT ineffective, while a high threshold for migration might allow the extra IGF-1 activation to contribute to enhanced migration.

It is well known that IGF-1 signaling is implicated in the migration of cancer cells [37-39]. However, only a few studies have shown potential involvement of IGF-1 in neural cell migration during development $[40,41]$. Interestingly, NSCs possess migratory ability toward injury or tumor foci. Several cytokines and growth factors and their receptors have been discovered to mediate the migration in these pathologic settings [30,31, 42, 43], but a potential role of IGF-1 signaling in this process has not been reported. Our in vitro experiments directly demonstrate that IGF-1 can induce chemotactic migration of NSCs, and that IGF$1 \mathrm{R}$ signaling in NSCs is required for the migration behavior. The signaling pathways that mediate robust migratory activity of NSCs toward glioma converge on PI3K [44]. Since PI3K is also an essential downstream target of IGF-1 signaling, it would be no surprise that IGF-1 plays a role in regulating the migration of NSCs.

Intriguingly, we observed dynamic motility of NSCs. Cultured neurospheres spontaneously moved from one place to another, and dynamic cytoplasmic protrusions and/or retractions were 
noticed along with the neurosphere movement. Actin-based cellular motility has been intensively studied in migratory cell types including leukocytes and tumor cells. Dynamic actin assemblies in the lamellipodia and filopodia, cytoplasmic protrusions at the moving edge of cells, provide contractile forces for cell migration $[45,46]$. Therefore, the amoeboid movement of NSCs observed in the present study may underlie the migratory behavior of NSCs in vitro and in the lesioned spinal cord in vivo. Indeed, it has been consistently demonstrated that NSCs are able to migrate toward or home in the site of brain injury [30,47,48], and the strong migratory ability of NSCs has been exploited to target brain tumor cells [49-52]. To the best of our knowledge, however, there is no report on the actin-based amoeboid motility of NSCs characterized by lamellipodia- or filopodia-like cytoplasmic protrusions. Only one study examined contractility and actin assembly of NSCs in the context of migration, but it did not directly demonstrate formation of actin-based cytoplasmic protrusions [53].

In the present study, the dynamic motility of NSCs was found to be dependent on IGF-1 signaling. Addition of IGF-1 and inhibition of IGF-1R increased and decreased the motility, respectively. Importantly, deletion of one allele of Igflr substantially compromised the motility of NSCs, providing explanation at a cellular level for the dramatic reduction of migration observed in the transplanted NSCs heterozygous for Igflr . Interestingly, IGF-1 stimulates motility in human neuroblastoma cells by promoting extension of lamellipodia [54]. The enhanced motility of neuroblastoma cells and other cell types due to IGF-1 treatment seems to be mediated by PI $3 \mathrm{~K}$ and its downstream effectors responsible for polymerization and depolymerization of actin filaments $[55,56]$. Our own experiment also showed that a PI $3 \mathrm{~K}$ inhibitor significantly attenuated the neurosphere movement and cytoplasmic protrusions. Therefore, our data indicate that IGF-1 signaling regulates the dynamic motility of NSCs by modulating PI3K activity.

In conclusion, the current study demonstrates that IGF-1 signaling in transplanted NSCs plays an important role in the regulation of survival and migration of NSC grafts in the lesioned spinal cord. Our data also provide evidence that the benefits of TMT in locomotor recovery are in part dependent on active IGF-1 signaling in the transplanted NSCs. In addition, TMT robustly enhanced migration of NSC grafts only with a full complement of IgfIr alleles, demonstrating that IGF-1 signaling acts as a critical mediator of the TMT-induced migration of NSC grafts in the lesioned spinal cord. We further revealed that dynamic motility of NSCs is regulated by IGF-1 signaling and suggest that this IGF-1-dependent NSC motility may be the cellular basis of the potent enhancement of NSC graft migration by TMT. Combination of transplantation of NSCs with activity-based neurorehabilitation interventions is a promising approach with the potential of clinical translation in the future. Notably, human patients with SCI exhibit reduced IGF-1 levels in blood or muscles [57-59], which are important peripheral sources for the IGF-1 available in the CNS [60]. Based on the results obtained in our study, it could be assumed that low IGF-1 levels would adversely influence the therapeutic benefits of NSC transplantation combined with neurorehabilitation interventions. Therefore, optimizing IGF-1 signaling in NSCs for transplantation may be justified when designing the combination strategy to maximize the therapeutic effectiveness.

\section{ACKNOWLEDGEMENTS}

This study was supported by the National Research Foundation of Korea (Grant NRF-2012R1A5A2048183, 2014M3A9B6034224, 2015R1A2A1A01003410, 2018R1A2A1A05020292 to B.G.K; NRF-2014R1A1A2056452, NRF-2017R1D1A1B03035100, to D.H.H.).

\section{REFERENCES}

1. Cusimano M, Biziato D, Brambilla E, Donegà M, Alfaro-Cervello C, Snider S, Salani G, Pucci F, Comi G, Garcia-Verdugo JM, De Palma M, Martino G, Pluchino S (2012) Transplanted neural stem/precursor cells instruct phagocytes and reduce secondary tissue damage in the injured spinal cord. Brain 135:447-460.

2. Peruzzotti-Jametti L, Bernstock JD, Vicario N, Costa AS, Kwok CK, Leonardi T, Booty LM, Bicci I, Balzarotti B, Volpe G, Mallucci G, Manferrari G, Donegà M, Iraci N, Braga A, Hallenbeck JM, Murphy MP, Edenhofer F, Frezza C, Pluchino S (2018) Macrophage-derived extracellular succinate licenses neural stem cells to suppress chronic neuroinflammation. Cell Stem Cell 22:355-368.e13.

3. Salewski RP, Mitchell RA, Li L, Shen C, Milekovskaia M, Nagy A, Fehlings MG (2015) Transplantation of induced pluripotent stem cell-derived neural stem cells mediate functional recovery following thoracic spinal cord injury through remyelination of axons. Stem Cells Transl Med 4:743-754.

4. Hawryluk GW, Mothe A, Wang J, Wang S, Tator C, Fehlings MG (2012) An in vivo characterization of trophic factor production following neural precursor cell or bone marrow stromal cell transplantation for spinal cord injury. Stem Cells Dev 21:2222-2238.

5. Yasuda A, Tsuji O, Shibata S, Nori S, Takano M, Kobayashi Y, Takahashi Y, Fujiyoshi K, Hara CM, Miyawaki A, Okano HJ, Toyama Y, Nakamura M, Okano H (2011) Significance of re- 
myelination by neural stem/progenitor cells transplanted into the injured spinal cord. Stem Cells 29:1983-1994.

6. Abematsu M, Tsujimura K, Yamano M, Saito M, Kohno K, Kohyama J, Namihira M, Komiya S, Nakashima K (2010) Neurons derived from transplanted neural stem cells restore disrupted neuronal circuitry in a mouse model of spinal cord injury. J Clin Invest 120:3255-3266.

7. Kadoya K, Lu P, Nguyen K, Lee-Kubli C, Kumamaru H, Yao L, Knackert J, Poplawski G, Dulin JN, Strobl H, Takashima Y, Biane J, Conner J, Zhang SC, Tuszynski MH (2016) Spinal cord reconstitution with homologous neural grafts enables robust corticospinal regeneration. Nat Med 22:479-487.

8. Bonner JF, Steward O (2015) Repair of spinal cord injury with neuronal relays: From fetal grafts to neural stem cells. Brain Res 1619:115-123.

9. Lu P, Kadoya K, Tuszynski MH (2014) Axonal growth and connectivity from neural stem cell grafts in models of spinal cord injury. Curr Opin Neurobiol 27:103-109.

10. Lee SI, Kim BG, Hwang DH, Kim HM, Kim SU (2009) Overexpression of Bcl-XL in human neural stem cells promotes graft survival and functional recovery following transplantation in spinal cord injury. J Neurosci Res 87:3186-3197.

11. Lu P, Wang Y, Graham L, McHale K, Gao M, Wu D, Brock J, Blesch A, Rosenzweig ES, Havton LA, Zheng B, Conner JM, Marsala M, Tuszynski MH (2012) Long-distance growth and connectivity of neural stem cells after severe spinal cord injury. Cell 150:1264-1273.

12. Ikegami T, Nakamura M, Yamane J, Katoh H, Okada S, Iwanami A, Watanabe K, Ishii K, Kato F, Fujita H, Takahashi T, Okano HJ, Toyama Y, Okano H (2005) Chondroitinase ABC combined with neural stem/progenitor cell transplantation enhances graft cell migration and outgrowth of growth-associated protein-43-positive fibers after rat spinal cord injury. Eur J Neurosci 22:3036-3046.

13. Hwang DH, Kim HM, Kang YM, Joo IS, Cho CS, Yoon BW, Kim SU, Kim BG (2011) Combination of multifaceted strategies to maximize the therapeutic benefits of neural stem cell transplantation for spinal cord repair. Cell Transplant 20:1361-1379.

14. Singhal S, Lawrence JM, Bhatia B, Ellis JS, Kwan AS, Macneil A, Luthert PJ, Fawcett JW, Perez MT, Khaw PT, Limb GA (2008) Chondroitin sulfate proteoglycans and microglia prevent migration and integration of grafted Müller stem cells into degenerating retina. Stem Cells 26:1074-1082.

15. Okada S, Ishii K, Yamane J, Iwanami A, Ikegami T, Katoh H, Iwamoto Y, Nakamura M, Miyoshi H, Okano HJ, Contag CH, Toyama Y, Okano H (2005) In vivo imaging of engrafted neu- ral stem cells: its application in evaluating the optimal timing of transplantation for spinal cord injury. FASEB J 19:18391841.

16. Roy RR, Harkema SJ, Edgerton VR (2012) Basic concepts of activity-based interventions for improved recovery of motor function after spinal cord injury. Arch Phys Med Rehabil 93:1487-1497.

17. Dobkin BH, Havton LA (2004) Basic advances and new avenues in therapy of spinal cord injury. Annu Rev Med 55:255282.

18. Sadowsky CL, McDonald JW (2009) Activity-based restorative therapies: concepts and applications in spinal cord injury-related neurorehabilitation. Dev Disabil Res Rev 15:112116.

19. Bonizzato M, Pidpruzhnykova G, DiGiovanna J, Shkorbatova P, Pavlova N, Micera S, Courtine G (2018) Brain-controlled modulation of spinal circuits improves recovery from spinal cord injury. Nat Commun 9:3015.

20. Capogrosso M, Milekovic T, Borton D, Wagner F, Moraud EM, Mignardot JB, Buse N, Gandar J, Barraud Q, Xing D, Rey E, Duis S, Jianzhong Y, Ko WK, Li Q, Detemple P, Denison T, Micera S, Bezard E, Bloch J, Courtine G (2016) A brain-spine interface alleviating gait deficits after spinal cord injury in primates. Nature 539:284-288.

21. Wenger N, Moraud EM, Gandar J, Musienko P, Capogrosso M, Baud L, Le Goff CG, Barraud Q, Pavlova N, Dominici N, Minev IR, Asboth L, Hirsch A, Duis S, Kreider J, Mortera A, Haverbeck O, Kraus S, Schmitz F, DiGiovanna J, van den Brand R, Bloch J, Detemple P, Lacour SP, Bézard E, Micera S, Courtine G (2016) Spatiotemporal neuromodulation therapies engaging muscle synergies improve motor control after spinal cord injury. Nat Med 22:138-145.

22. Gill ML, Grahn PJ, Calvert IS, Linde MB, Lavrov IA, Strommen JA, Beck LA, Sayenko DG, Van Straaten MG, Drubach DI, Veith DD, Thoreson AR, Lopez C, Gerasimenko YP, Edgerton VR, Lee KH, Zhao KD (2018) Neuromodulation of lumbosacral spinal networks enables independent stepping after complete paraplegia. Nat Med 24:1677-1682.

23. Hwang DH, Shin HY, Kwon MJ, Choi JY, Ryu BY, Kim BG (2014) Survival of neural stem cell grafts in the lesioned spinal cord is enhanced by a combination of treadmill locomotor training via insulin-like growth factor-1 signaling. J Neurosci 34:12788-12800.

24. Holzenberger M, Dupont J, Ducos B, Leneuve P, Géloën A, Even PC, Cervera P, Le Bouc Y (2003) IGF-1 receptor regulates lifespan and resistance to oxidative stress in mice. Nature 421:182-187. 
25. Azari H, Sharififar S, Rahman M, Ansari S, Reynolds BA (2011) Establishing embryonic mouse neural stem cell culture using the neurosphere assay. J Vis Exp. pii: 2457.

26. Yu D, Neeley WL, Pritchard CD, Slotkin JR, Woodard EJ, Langer R, Teng YD (2009) Blockade of peroxynitrite-induced neural stem cell death in the acutely injured spinal cord by drug-releasing polymer. Stem Cells 27:1212-1222.

27. Wang Q, Chuikov S, Taitano S, Wu Q, Rastogi A, Tuck SJ, Corey JM, Lundy SK, Mao-Draayer Y (2015) Dimethyl fumarate protects neural stem/progenitor cells and neurons from oxidative damage through Nrf2-ERK1/2 MAPK Pathway. Int J Mol Sci 16:13885-13907.

28. Barandalla M, Haucke E, Fischer B, Navarrete Santos A, Colleoni S, Galli C, Navarrete Santos A, Lazzari G (2017) Comparative analysis of AGE and RAGE levels in human somatic and embryonic stem cells under $\mathrm{H}_{2} \mathrm{O}_{2}$-induced noncytotoxic oxidative stress conditions. Oxid Med Cell Longev 2017:4240136.

29. Liu JP, Baker J, Perkins AS, Robertson EJ, Efstratiadis A (1993) Mice carrying null mutations of the genes encoding insulinlike growth factor I (Igf-1) and type 1 IGF receptor (Igflr). Cell 75:59-72.

30. Imitola J, Raddassi K, Park KI, Mueller FJ, Nieto M, Teng YD, Frenkel D, Li J, Sidman RL, Walsh CA, Snyder EY, Khoury SJ (2004) Directed migration of neural stem cells to sites of CNS injury by the stromal cell-derived factor 1alpha/CXC chemokine receptor 4 pathway. Proc Natl Acad Sci U S A 101:1811718122.

31. Sun L, Lee J, Fine HA (2004) Neuronally expressed stem cell factor induces neural stem cell migration to areas of brain injury. J Clin Invest 113:1364-1374.

32. Flynn JR, Dunn LR, Galea MP, Callister R, Callister RJ, Rank MM (2013) Exercise training after spinal cord injury selectively alters synaptic properties in neurons in adult mouse spinal cord. J Neurotrauma 30:891-896.

33. Edgerton VR, Tillakaratne NJ, Bigbee AJ, De Leon RD, Roy RR (2004) Plasticity of the spinal neural circuitry after injury. Annu Rev Neurosci 27:145-167.

34. Schucht P, Raineteau O, Schwab ME, Fouad K (2002) Anatomical correlates of locomotor recovery following dorsal and ventral lesions of the rat spinal cord. Exp Neurol 176:143153.

35. Sroga JM, Jones TB, Kigerl KA, McGaughy VM, Popovich PG (2003) Rats and mice exhibit distinct inflammatory reactions after spinal cord injury. J Comp Neurol 462:223-240.

36. Hong LT, Kim YM, Park HH, Hwang DH, Cui Y, Lee EM, Yahn S, Lee JK, Song SC, Kim BG (2017) An injectable hydro- gel enhances tissue repair after spinal cord injury by promoting extracellular matrix remodeling. Nat Commun 8:533.

37. Mytilinaiou M, Nikitovic D, Berdiaki A, Papoutsidakis A, Papachristou DJ, Tsatsakis A, Tzanakakis GN (2017) IGFI regulates HT1080 fibrosarcoma cell migration through a syndecan-2/Erk/ezrin signaling axis. Exp Cell Res 361:9-18.

38. D’Alessandro R, Refolo MG, Lippolis C, Carella N, Messa C, Cavallini A, Carr BI (2018) Strong enhancement by IGF1-R antagonists of hepatocellular carcinoma cell migration inhibition by Sorafenib and/or vitamin K1. Cell Oncol (Dordr) 41:283-296.

39. André F, Rigot V, Thimonier J, Montixi C, Parat F, Pommier G, Marvaldi J, Luis J (1999) Integrins and E-cadherin cooperate with IGF-I to induce migration of epithelial colonic cells. Int J Cancer 83:497-505.

40. Maucksch C, McGregor AL, Yang M, Gordon RJ, Yang M, Connor B (2013) IGF-I redirects doublecortin-positive cell migration in the normal adult rat brain. Neuroscience 241:106-115.

41. Hurtado-Chong A, Yusta-Boyo MJ, Vergaño-Vera E, Bulfone A, de Pablo F, Vicario-Abejón C (2009) IGF-I promotes neuronal migration and positioning in the olfactory bulb and the exit of neuroblasts from the subventricular zone. Eur J Neurosci 30:742-755.

42. Magge SN, Malik SZ, Royo NC, Chen HI, Yu L, Snyder EY, O'Rourke DM, Watson DJ (2009) Role of monocyte chemoattractant protein-1 (MCP-1/CCL2) in migration of neural progenitor cells toward glial tumors. J Neurosci Res 87:15471555.

43. Schmidt NO, Przylecki W, Yang W, Ziu M, Teng Y, Kim SU, Black PM, Aboody KS, Carroll RS (2005) Brain tumor tropism of transplanted human neural stem cells is induced by vascular endothelial growth factor. Neoplasia 7:623-629.

44. Kendall SE, Najbauer J, Johnston HF, Metz MZ, Li S, Bowers M, Garcia E, Kim SU, Barish ME, Aboody KS, Glackin CA (2008) Neural stem cell targeting of glioma is dependent on phosphoinositide 3-kinase signaling. Stem Cells 26:1575-1586.

45. Mattila PK, Lappalainen P (2008) Filopodia: molecular architecture and cellular functions. Nat Rev Mol Cell Biol 9:446454.

46. Carlier MF, Pantaloni D (2007) Control of actin assembly dynamics in cell motility. J Biol Chem 282:23005-23009.

47. Garzón-Muvdi T, Quiñones-Hinojosa A (2009) Neural stem cell niches and homing: recruitment and integration into functional tissues. ILAR J 51:3-23.

48. Chang DJ, Moon H, Lee YH, Lee N, Lee HJ, Jeon I, Lee H, Hwang TS, Oh SH, Shin DA, Kim SU, Hong KS, Song J (2012) 
In vivo tracking of human neural stem cells following transplantation into a rodent model of ischemic stroke. Int J Stem Cells 5:79-83.

49. Bagó JR, Alfonso-Pecchio A, Okolie O, Dumitru R, Rinkenbaugh A, Baldwin AS, Miller CR, Magness ST, Hingtgen SD (2016) Therapeutically engineered induced neural stem cells are tumour-homing and inhibit progression of glioblastoma. Nat Commun 7:10593.

50. Bagó JR, Okolie O, Dumitru R, Ewend MG, Parker JS, Werff RV, Underhill TM, Schmid RS, Miller CR, Hingtgen SD (2017) Tumor-homing cytotoxic human induced neural stem cells for cancer therapy. Sci Transl Med 9:eaah6510.

51. Aboody KS, Brown A, Rainov NG, Bower KA, Liu S, Yang W, Small JE, Herrlinger U, Ourednik V, Black PM, Breakefield XO, Snyder EY (2000) Neural stem cells display extensive tropism for pathology in adult brain: evidence from intracranial gliomas. Proc Natl Acad Sci U S A 97:12846-12851.

52. Aboody KS, Najbauer J, Metz MZ, D’Apuzzo M, Gutova M, Annala AJ, Synold TW, Couture LA, Blanchard S, Moats RA, Garcia E, Aramburo S, Valenzuela VV, Frank RT, Barish ME, Brown CE, Kim SU, Badie B, Portnow J (2013) Neural stem cell-mediated enzyme/prodrug therapy for glioma: preclinical studies. Sci Transl Med 5:184ra59.

53. Yan S, Li P, Wang Y, Yu W, Qin A, Liu M, Xiang AP, Zhang W, Li W (2016) Nestin regulates neural stem cell migration via controlling the cell contractility. Int J Biochem Cell Biol 78:349360.
54. Meyer GE, Shelden E, Kim B, Feldman EL (2001) Insulin-like growth factor I stimulates motility in human neuroblastoma cells. Oncogene 20:7542-7550.

55. Meyer G, Kim B, van Golen C, Feldman EL (2005) Cofilin activity during insulin-like growth factor I-stimulated neuroblastoma cell motility. Cell Mol Life Sci 62:461-470.

56. Cheng HL, Steinway ML, Russell JW, Feldman EL (2000) GTPases and phosphatidylinositol 3-kinase are critical for insulin-like growth factor-I-mediated Schwann cell motility. J Biol Chem 275:27197-27204.

57. Otzel DM, Lee J, Ye F, Borst SE, Yarrow JF (2018) Activitybased physical rehabilitation with adjuvant testosterone to promote neuromuscular recovery after spinal cord injury. Int J Mol Sci 19:E1701.

58. Bauman WA, Spungen AM, Flanagan S, Zhong YG, Alexander LR, Tsitouras PD (1994) Blunted growth hormone response to intravenous arginine in subjects with a spinal cord injury. Horm Metab Res 26:152-156.

59. Léger B, Senese R, Al-Khodairy AW, Dériaz O, Gobelet C, Giacobino JP, Russell AP (2009) Atrogin-1, MuRF1, and FoXO, as well as phosphorylated GSK-3beta and 4E-BP1 are reduced in skeletal muscle of chronic spinal cord-injured patients. Muscle Nerve 40:69-78.

60. Fernandez AM, Torres-Alemán I (2012) The many faces of insulin-like peptide signalling in the brain. Nat Rev Neurosci 13:225-239. 